\title{
Endogenous Gradients of Resting Potential Instructively Pattern Embryonic Neural Tissue via Notch Signaling and Regulation of Proliferation
}

\author{
Vaibhav P. Pai, ${ }^{1}$ OJoan M. Lemire, ${ }^{1}$ Jean-François Paré, ${ }^{1}$ Gufa Lin, ${ }^{2}$ Ying Chen, ${ }^{2}$ and Michael Levin ${ }^{1}$ \\ ${ }^{1}$ Biology Department, Center for Regenerative and Developmental Biology, Tufts University, Medford, Massachusetts 02155-4243 and ${ }^{2}$ Stem Cell Institute, \\ University of Minnesota, Minneapolis, Minnesota 55455
}

\begin{abstract}
Biophysical forces play important roles throughout embryogenesis, but the roles of spatial differences in cellular resting potentials during large-scale brain morphogenesis remain unknown. Here, we implicate endogenous bioelectricity as an instructive factor during brain patterning in Xenopus laevis. Early frog embryos exhibit a characteristic hyperpolarization of cells lining the neural tube; disruption of this spatial gradient of the transmembrane potential $\left(V_{\mathrm{mem}}\right)$ diminishes or eliminates the expression of early brain markers, and causes anatomical mispatterning of the brain, including absent or malformed regions. This effect is mediated by voltage-gated calcium signaling and gap-junctional communication. In addition to cell-autonomous effects, we show that hyperpolarization of transmembrane potential $\left(V_{\mathrm{mem}}\right)$ in ventral cells outside the brain induces upregulation of neural cell proliferation at long range. Misexpression of the constitutively active form of Notch, a suppressor of neural induction, impairs the normal hyperpolarization pattern and neural patterning; forced hyperpolarization by misexpression of specific ion channels rescues brain defects induced by activated Notch signaling. Strikingly, hyperpolarizing posterior or ventral cells induces the production of ectopic neural tissue considerably outside the neural field. The hyperpolarization signal also synergizes with canonical reprogramming factors ( $P O U$ and $H B 4$ ), directing undifferentiated cells toward neural fate in vivo. These data identify a new functional role for bioelectric signaling in brain patterning, reveal interactions between $V_{\text {mem }}$ and key biochemical pathways (Notch and $\mathrm{Ca}^{2+}$ signaling) as the molecular mechanism by which spatial differences of $V_{\text {mem }}$ regulate organogenesis of the vertebrate brain, and suggest voltage modulation as a tractable strategy for intervention in certain classes of birth defects.
\end{abstract}

Key words: bioelectricity; brain morphogenesis; long range; proliferation; resting potential

\section{Introduction}

The embryonic CNS is a paradigm case of complex morphogenesis within which to decode the biophysical forces that enable pattern formation. Understanding the convergence of genetic and physiological signaling toward large-scale anatomy of the brain holds enormous biomedical potential for addressing birth

Received May 7, 2014; revised Dec. 21, 2014; accepted Jan. 14, 2015.

Author contributions:V.P.P. and M.L. designed research;V.P.P., J.M.L., J.-F.P., G.L., and Y.C. performed research; J.M.L., J.-F.P., and G.L. contributed unpublished reagents/analytic tools; V.P.P., G.L., and M.L. analyzed data; V.P.P. and M.L. wrote the paper.

We gratefully acknowledge support of the National Institutes of Health (AR055993-01), National Science Foundation (CBET-0939511), and the G. Harold and Leila Y. Mathers Charitable Foundation. We thank Amber Brand, Erin Switzer, and Amanda Allen for Xenopus husbandry and general lab assistance; Dany Adams for help with microscopy; Elena Casey and Dale Frank for the POU construct; Sally Moody for the chordin antisense probe; Eddy DeRobertis for the cerberus antisense probe; John Gurdon and Welcome Trust UK for HB4 construct; Daryl Davies and Miriam Fine for the GlyR expression construct; Florian Lang for Kv1.5 plasmid; Manuel Kukuljan for Nav1.5 construct; Sherry Aw for DNKir6.1p construct; Valerie Schneider for otx 2 antisense probe; Gerald Eagleson for bf1 and emx antisense probes; David Paul for $\mathrm{H} 7$ construct; $H$ H. Sakurai and A. Miyawaki for FUCCI constructs; and Randy Blakely for DN-SERT construct.

The authors declare no competing financial interests.

Correspondence should be addressed to Dr. Michael Levin, Biology Department, Center for Regenerative and Developmental Biology, Tufts University, 200 Boston Avenue, Suite 4600, Medford, MA 02155-4243. E-mail: michael.levin@tufts.edu.

DOI:10.1523/JNEUROSCI.1877-14.2015

Copyright $\odot 2015$ the authors $\quad 0270-6474 / 15 / 354366-20 \$ 15.00 / 0$ defects and repairing injuries. The tightly orchestrated proliferation and expansion of the neural progenitor population underlie formation of a complex brain from the pseudostratified neuroepithelial tube (Joseph and Hermanson, 2010). Organ size and target morphology are precisely controlled in all life forms from plants to vertebrates (Stanger, 2008). Appropriate organ size is achieved through extensive proliferation, growth, and remodeling during development (Stanger, 2008; Joseph and Hermanson, 2010), but the mechanisms that encode this information and ensure appropriate size and morphology remain largely unknown. Both physical forces/properties (Thompson, 1942; Stanger, 2008), as well as genetic developmental programs (Zhao et al., 2011; Harvey and Hariharan, 2012), are involved. Here, we reveal a new morphogenetic role for transmembrane voltage potential as regulator of brain morphogenesis, and investigate the mechanisms by which $V_{\text {mem }}$ distribution contributes to the development of the vertebrate brain.

The idea that spatiotemporal electrical gradients across tissue direct growth and form was proposed many decades ago (Burr, 1932). This has since been investigated in the context of electric fields' roles in cell migration, regeneration, and wound healing (McCaig et al., 2005; Pullar, 2011). Recently, a new aspect of developmental physiology—spatiotemporal patterns of trans- 
membrane potential $\left(V_{\mathrm{mem}}\right)$ of cells across tissues in vivo-was revealed as a key regulator of patterning (Sundelacruz et al., 2009; Vandenberg and Levin, 2010; Beane et al., 2013; Levin, 2013; Tseng and Levin, 2013; Perathoner et al., 2014). Tightly regulated differences in $V_{\text {mem }}$ among key cell groups establish anatomical polarity, positional information, and organ identity during vertebrate appendage regeneration (Monteiro et al., 2014; Perathoner et al., 2014), cancer initiation and metastasis (Brown et al., 1994; Brackenbury, 2012), eye formation (Nuckels et al., 2009; Vandenberg et al., 2011; Pai et al., 2012b), left-right patterning (Levin et al., 2002; Adams et al., 2006), and planarian head induction and patterning (Beane et al., 2013).

It has long been known that electrical spiking activity of neurons regulates neurogenesis (Deisseroth et al., 2004; Spitzer, 2006; Swapna and Borodinsky, 2012). Here, we asked whether the resting electrical properties of neural precursor cells, and importantly their neighbors, might regulate large-scale patterning of the CNS. Could information encoded in steady-state properties (not action potentials) of embryonic cells direct neural induction, differentiation, and gene expression during formation of a complex brain? Embryos of Xenopus laevis are an excellent model for neurodevelopment and its disorders (Pratt and Khakhalin, 2013), and uniquely suited for biophysics experiments. Our data indicate that endogenous transmembrane potential gradients $\left(V_{\text {mem }}\right)$ play important roles during neural induction and neural tissue development. These effects of $V_{\text {mem }}$ change are mediated by gap junctions (GJ) and $\mathrm{Ca}^{2+}$ flux, and regulate key transcription factors within developing neural tissue. $V_{\text {mem }}$ levels also regulate tissue size via long-range control over cell proliferation. Remarkably, reinforcing these powerful endogenous signals can rescue brain morphology defects, while misexpression of ion channels induces ectopic neural tissue well outside the endogenous neural fields. These results suggest a new modality for therapeutic applications in nervous system development and disease.

\section{Materials and Methods}

Animal husbandry. Xenopus laevis embryos were fertilized in vitro according to standard protocols (Sive et al., 2000) in $0.1 \times$ Marc's Modified Ringer's (MMR; $10 \mathrm{mM} \mathrm{Na}^{+}, 0.2 \mathrm{mM} \mathrm{K}^{+}, 10.5 \mathrm{mM} \mathrm{Cl}^{-}$, and $0.2 \mathrm{~mm}$ $\mathrm{Ca}^{2+}, \mathrm{pH}$ 7.8). Intracellular ion concentrations in Xenopus embryos are as follows: $21 \mathrm{mM} \mathrm{Na}^{+}, 90 \mathrm{mM} \mathrm{K}^{+}, 60 \mathrm{~mm} \mathrm{Cl}^{-}$, and $0.5 \mathrm{mM} \mathrm{Ca}^{2+}$ (Gillespie, 1983). Xenopus embryos were housed at $14-18^{\circ} \mathrm{C}\left(14^{\circ} \mathrm{C}\right.$ overnight after injection and subsequently at $18^{\circ} \mathrm{C}$ ) and staged according to Nieuwkoop and Faber (1967). PNTub::GFP transgenic Xenopus were created as described previously (Kroll and Amaya, 1996) except that the restriction enzyme was omitted (Marsh-Armstrong et al., 1999; Lin et al., 2012). There is no practical way to precisely determine the sex of the embryos at the stages at which these procedures are done, and the ratio of male:female should be 50:50 in all of our experiments. All experiments were approved by the Tufts University Animal Research Committee (M2011-70) in accordance with the guide for care and use of laboratory animals.

Microinjections. Capped synthetic mRNAs generated using mMessage mMachine kit (Ambion) were dissolved in nuclease-free water and injected into embryos immersed in 3\% Ficoll using standard methods (Sive et al., 2000). Each injection delivered between 1 and $2 \mathrm{nl}$ or 1-2 ng of mRNA (per blastomere) into the embryos, usually at four-cell stage into the middle of the cell in the animal pole. Constructs used were as follows: constitutively active notch intracellular domain (Notch ICD; Beck and Slack, 1999), POU (Snir et al., 2006), HB4 (Jullien et al., 2010), Kv1.5 (Strutz-Seebohm et al., 2007), GlyR (Davies et al., 2003), dominantnegative Kir6.1 pore mutant (Aw et al., 2010), Bir10 (Fakler et al., 1996), 666 chimera (Hough et al., 2000), Nav1.5 (Onkal et al., 2008), H7 (Paul et al., 1995), and dominant-negative SERT mutant D98G (Barker et al.,
1999; Fukumoto et al., 2005b). Kv1.5- $\beta$-galactosidase and Kv1.5-tomato were injected as single mRNAs (bicistronic constructs with single polyA tail at the end) that produce separate proteins, due to a viral peptide sequence (2A) inserted between the 2 cDNA sequences (de Felipe et al., 2006; Szymczak-Workman et al., 2012).

Kv1.5 is a commonly used hyperpolarizing channel (Bertoli et al., 1994; Strutz-Seebohm et al., 2007; Pai et al., 2012b). GlyR is a particularly versatile reagent because it allows the experimental control of $V_{\text {mem }}$ in either direction, using the GlyR opener drug ivermectin (IVM) (Shan et al., 2001) coupled with modulation of the extracellular chloride levels $\left[\mathrm{Cl}^{-}\right]_{\text {ex }}$ (Blackiston et al., 2011). The normally depolarizing effect of GlyR misexpression in standard Xenopus medium $(0.4 \mathrm{~mm})\left[\mathrm{Cl}^{-}\right]$becomes a hyperpolarizing effect by incubating embryos in the presence of $\left[\mathrm{Cl}^{-}\right]_{\mathrm{ex}}$ higher than intracellular chloride $\left[\mathrm{Cl}^{-}\right]_{\text {in }}(\sim 60 \mathrm{~mm})$ (Davies et al., 2003; Blackiston et al., 2011; Pai et al., 2012b) as this condition drives the influx of negative ions.

The two fluorescent ubiquitinylation-based cell-cycle indicator mRNA constructs were used as previously documented (Sakaue-Sawano et al., 2008). The two mRNA constructs, $m K O 2-z C d t 1$ (red insert for $\mathrm{G}_{1}$ phase) and $m A G-z G e m i n i n$ (green insert for $S / G_{2} / M$ phase), were used in a 1:2 ratio and injected in both cells at the two-cell stage for an even distribution within the embryo.

Imaging $V_{\text {mem }}$ using CC2-DMPE:DiBAC 4 (3). CC2-DMPE and $\mathrm{DiBAC}_{4}(3)$ voltage reporter dyes were obtained from Invitrogen and used as per the standard protocol, including dark-field and flat-field correction (Adams and Levin, 2012). Briefly, the use of two dyes with opposite emission profiles simultaneously provides an internal control and allows ratiometric normalization. CC2-DMPE stock (5 mM) was dissolved 1:1000 in $0.1 \times$ MMR and the embryos were incubated in the dark in this solution for at least $1 \mathrm{~h}$ followed by washes with $0.1 \times \mathrm{MMR} \operatorname{DiBAC}_{4}(3)$ stocks $(1.9 \mathrm{mM})$ were dissolved 1:4000 in 0.1 $\times$ MMR and the CC2-DMPE-stained embryos were then incubated in the dark in this solution for at least $30 \mathrm{~min}$ followed by visualization under the microscope. An Olympus BX-61 microscope equipped with a Hamamatsu ORCA AG CCD camera, and controlled by MetaMorph software (Molecular Devices), was used to collect signal. NIH ImageJ software was used to quantify the fluorescence intensities of the CC2-DMPE:DiBAC signal.

In situ hybridization. Xenopus embryos were collected and fixed in MEMFA (Sive et al., 2000) and in situ hybridization was performed as previously described (Harland, 1991; Sive et al., 2000). The embryos were washed with PBS $0.1 \%$ Tween 20 (PBST) and transferred through series of methanol washes $25-50 \%$ to $75-100 \%$. In situ antisense probes were generated in vitro from linearized templates using a DIG-labeling mix (Roche). Chromogenic reaction times were optimized for signal-tobackground ratio. Probes used were otx2 (Pannese et al., 1995), chordin (Sasai et al., 1994), cerberus (Bouwmeester et al., 1996), bfl, and emx (Eagleson et al., 2001; Eagleson and Theisen, 2008). NIH ImageJ software was used to quantify the in situ signal intensities.

Immunofluorescence and immunohistochemistry. Spatial detection of proliferation was performed by immunofluorescence for histone $\mathrm{H} 3 \mathrm{P}$ on sections. Briefly, embryos were fixed overnight in MEMFA at $4^{\circ} \mathrm{C}$ (Sive et al., 2000), embedded in agarose, and sectioned at $100 \mu \mathrm{M}$ thickness using a Leica vibratome (VT1000S) as per standard protocol (Blackiston et al., 2010) or embedded in paraffin and sectioned at $5 \mu \mathrm{M}$ thickness using Leica microtome as per the standard protocol (Sive et al., 2000). The sections were permeabilized in PBS $0.1 \%$ Triton X-100; antigen retrieved using citrate buffer, pH 6.0 (heating in a microwave); blocked with $10 \%$ goat serum in PBST for $1 \mathrm{~h}$ at room temperature; and incubated at $4^{\circ} \mathrm{C}$ overnight with primary antibody (Anti-H3P; Millipore-Invitrogen 04817) for proliferation at 1:1000 dilution in PBST $+10 \%$ goat serum (blocking buffer). Sections were washed six times in PBST and incubated with Alexa Fluor-conjugated fluorescent secondary antibody (Invitrogen) at 1:1000 dilution in PBST $10 \%$ goat serum overnight at $4^{\circ} \mathrm{C}$. Sections were washed six times in PBST and photographed using an Olympus BX-61 microscope equipped with a Hamamatsu ORCA AG CCD camera, and controlled by MetaMorph software.

For ectopic neural tissue detection immunochemistry was performed on whole embryos. Briefly, embryos were fixed in MEMFA (Sive et al., 2000) and blocked with PBST 5\% goat serum incubated in primary an- 


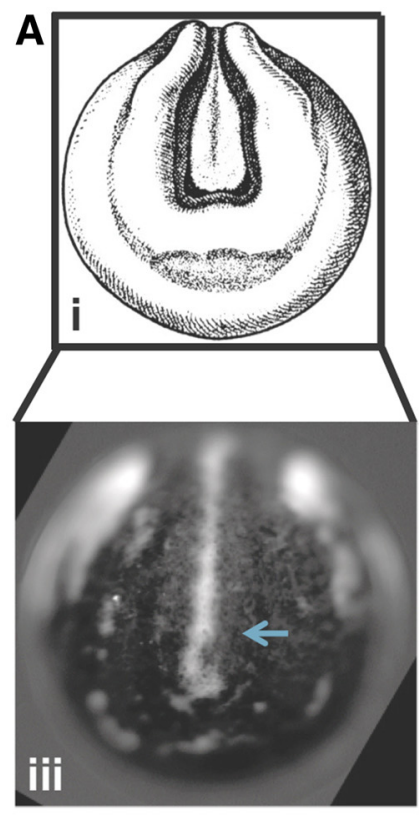

Stage 16

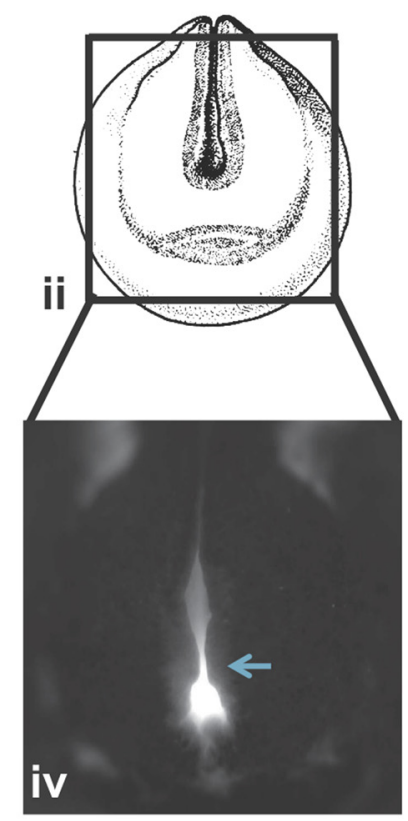

Stage 18

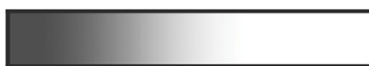

Relatively depolarized

Relatively hyperpolarized

D $\square=$ Area of measurement

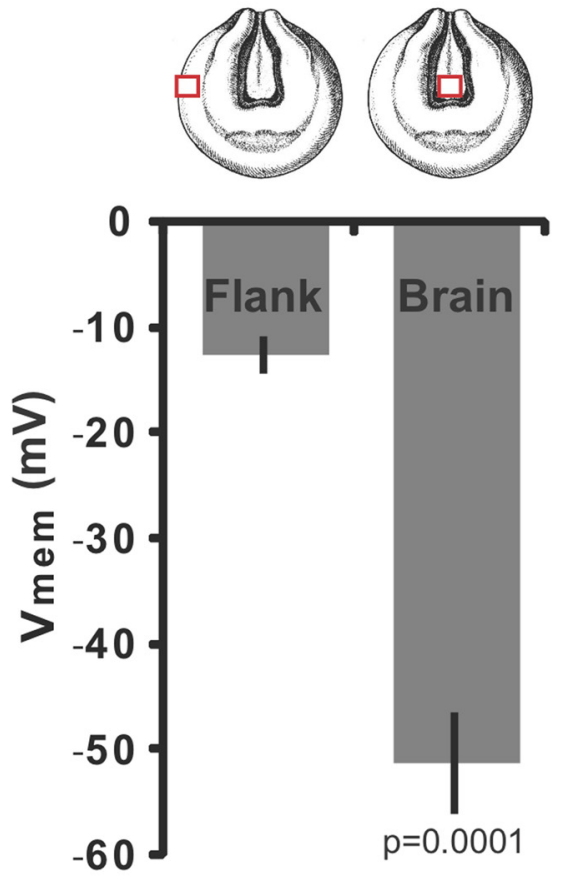

B

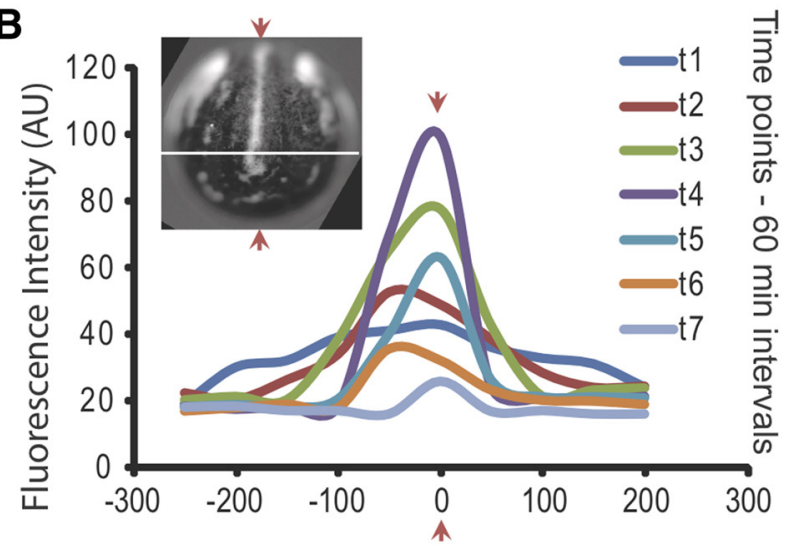

C

Distance in Pixels from midline

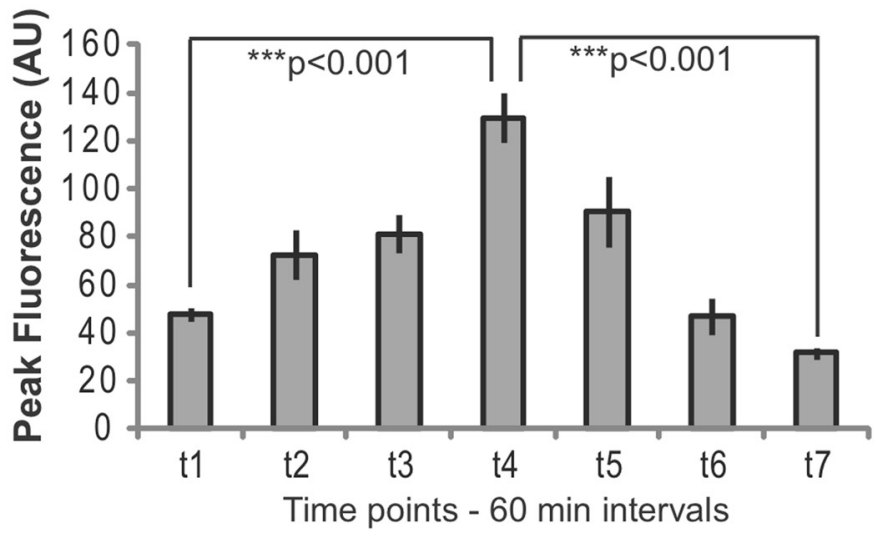

Stage $14 \longrightarrow$ Development $\longrightarrow$ Stage 20

Figure 1. A distinct and intense hyperpolarization of cells lining the neural tube exists before neural tube closure. A, Representative CC2-DMPE:DiBAC staining (Aiii, Aiv) of indicated regions (Ai, Aii) of Xenopus embryos at stages 16 and 18. Blue arrows mark the cluster of intensely hyperpolarized cells in the anterior neural field. (Figure legend continues.) 
tibody for Sox2 (Cell Signaling Technology, CST-2748S) or NCAM (Abcam ab5032) at 1:500 dilution in the blocking solution. Horseradish peroxidase-conjugated secondary antibody (Invitrogen) was used at 1:1000 dilution and color was developed with DAB Kit (Vector Laboratories SK-4100).

Drug exposure. Xenopus embryos were incubated in pharmacological blockers or channel openers dissolved in $0.1 \times$ MMR during the stages of interest as indicated in respective experiments followed by several washes with $0.1 \times$ MMR. Embryos were exposed (from stage 10 to 30 unless otherwise specified, because neural/brain tissue development takes place in this time period, allowing specific testing of effects on these processes while allowing cleavage and gastrulation to proceed normally) to the following: $10 \mu \mathrm{M}$ IVM (Sigma), $5 \mu \mathrm{M}$ verapamil (Sigma), $200 \mu \mathrm{M}$ Lindane (Sigma), $10 \mu \mathrm{M}$ fluoxetine (Tocris Bioscience), $10 \mu \mathrm{m}$ sertraline (Tocris Bioscience), $0.2 \mathrm{~m}$ lithium chloride (LiCl; Sigma; $10 \mathrm{~min}$ at 32-cell stage), or UV light (75 s at one-cell stage; UVP Transilluminator Model M-15).

Intracellular recordings from embryo cells. Membrane potentials were measured using an oocyte clamp OC-725C amplifier (Warner Instruments) with a single voltage electrode. Microelectrodes were made from thin-walled borosilicate glass pulled with a flaming/brown micropipette puller (p-97; Sutter Instruments) and back-filled with electrode solution ( $2 \mathrm{~m}$ potassium acetate, $10 \mathrm{~mm} \mathrm{KCl}$, and $5 \mathrm{~mm}$ HEPES, pH 7.5). Tip resistances were $80-100 \mathrm{M} \Omega$. Electrode penetration of ectodermal cells was by visual guidance on a fixed-stage microscope (Zeiss) using a threeaxis micromanipulator.

Statistics. All statistical analyses were performed using Microsoft Excel. Data were either pooled from various iterations, with $\chi^{2}$ square analysis performed on them, or data from various iterations were analyzed by $t$ test (for two groups) or ANOVA (for more than two groups).

\section{Results \\ Cells lining the neural tube show specific hyperpolarization before neural tube closure in Xenopus}

A study of endogenous bioelectrical patterns during craniofacial development (Vandenberg et al., 2011) showed a strong hyperpolarization signal from the cells of the neural plate, as the neural folds are formed and close to form the neural tube. To characterize in detail the changes in diverse resting potential $\left(V_{\text {mem }}\right)$ states across neural development, we used in vivo time-lapse imaging with the voltage-sensitive dye pair CC2-DMPE:DiBAC (Adams and Levin, 2012). During neurulation, the neural folds remain relatively depolarized while the neural plate cells exhibit hyperpolarization (Fig. $1 A$, blue arrows; $n=23$ ); this begins as early as the start of neural fold formation (stage 12; data not shown) of Xenopus embryos; this signal progressively intensifies until the closure of the neural tube at which point the signal can no longer be seen (Fig. 1 B, $C ; n=10$; Vandenberg et al., 2011). Whole-cell electrophysiological recordings of $V_{\text {mem }}$ from the neural plate cells (approximately $-51 \mathrm{mV}$; stages $16-17$ ) showed them to be hyperpolarized by $\sim 40 \mathrm{mV}$ compared with the neighboring cells (Fig. $1 D ; n=5, p=0.0001$ ). The presence of distinct resting

\section{$\leftarrow$}

(Figure legend continued.) The hyperpolarization begins well before the neural tube closure ( $N=23$ embryos). Illustrations reproduced with permission from Nieuwkoop and Faber, 1967). $\boldsymbol{B}$, Fluorescence intensity measurements of CC2-DMPE:DiBAC-stained embryo along the indicated axis (white line in inset) at multiple time points (t1-t7) during development from stage 14-20. Representative set of measurements from among 10 different embryos analyzed $(\boldsymbol{C})$ showed the transformation of broad low-intensity hyperpolarization becoming focused highintensity hyperpolarization before diminishing to background levels during neurulation. $\mathbf{C}$, Quantification of CC2-DMPE:DiBAC peak fluorescence intensities at each of the time points (stages $14-20)$ in developing embryos $(n=10)$. A one-way ANOVA analysis showed that at time point $t 4$ the peak fluorescence intensity is significantly different than $\mathrm{t} 1$ and $\mathrm{t}$. Data are presented as mean $\pm S E M,{ }^{* * *} p<0.001 . D$, Electrophysiological $V_{\text {mem }}$ measurements of cells stained with CC2-DMPE:DiBAC in areas as indicated. Readings were recorded from five embryos. Values are plotted as mean \pm SEM. Data were analyzed by paired $t$ test and $p=0.0001$. potentials across the neural plate, and the dynamic nature of $V_{\text {mem }}$ change at these crucial stages of development, suggested that these gradients may function as regulators of induction and formation of neural tissue.

\section{Local perturbation of $V_{\text {mem }}$ causes disruption of endogenous brain development}

The experimental alteration of resting potential (in either direction-depolarizing or hyperpolarizing), induced by misexpression of dominant channels, is a strategy often used to identify functional roles for $V_{\text {mem }}$ regulation in embryonic and regenerative patterning (Levin et al., 2002; Adams et al., 2006; 2013; Aw et al., 2008; Vandenberg et al., 2011; Pai et al., 2012b; Perathoner et al., 2014). We specifically altered the $V_{\text {mem }}$ of cells within the relevant regions by injecting mRNAs encoding either $K v 1.5$ (voltage-gated potassium channel, hyperpolarizing; StrutzSeebohm et al., 2007) or GlyR (glycine-gated chloride channel $\alpha$-1, depolarizing; Davies et al., 2003). The effect of each introduced ion channel on the $V_{\text {mem }}$ of cells in the embryo was evaluated at stages 10-21 using the voltage reporter dyes (Fig. 2A; Pai et al., 2012b).

Ion channel mRNA (titrated to the lowest levels that produced brain phenotypes) was injected into the two dorsal cells of the four-cell embryo (the blastomeres from which the neural tissue is derived; Moody, 1987). As in our many previous studies, we saw no sign of general toxicity or ill health (midline patterning, overall growth rate, scale proportions, and behavior were normal; Blackiston et al., 2011; Adams and Levin, 2013). GlyR-injected embryos that were not treated with IVM, the channel opener, showed a similar $V_{\text {mem }}$ pattern to uninjected controls (Fig. $2 \mathrm{~A}$ ). $G l y R$-injected embryos in the presence of IVM and with normal levels of $\mathrm{Cl}^{-}$in the medium were depolarized due to efflux of chloride ions (Blackiston et al., 2011; 2015; Pai et al., 2012b). When those embryos were instead kept in $70 \mathrm{mM} \mathrm{Cl}^{-}$the embryos became hyperpolarized (due to influx of anions; see Materials and Methods for details). Kv1.5 and $G l y R+70 \mathrm{mM} \mathrm{Cl}^{-}$ (IVM) both efficiently hyperpolarized 21 of 24 (87.5\%) and 11 of $14(78.6 \%)$ embryos, respectively, and GlyR (IVM) efficiently depolarized 18 of 27 (66.7\%) embryos (Figure 2A; Pai et al., $2012 \mathrm{~b}$ ). These treatments eliminated or strongly disrupted the endogenous $V_{\text {mem }}$ pattern in the developing neural tube (Figure 2A; Pai et al., 2012b).

Are the endogenous patterns of differential hyperpolarization required for normal brain tissue development? To determine this, embryos injected as above (disrupting in both depolarizing and hyperpolarizing directions the normal, spatially heterogeneous distribution of differential $V_{\text {mem }}$ in the anterior of embryo; Fig. 2A; Brown et al., 1994; Pai et al., 2012b) were allowed to develop to stage 45 , and brain morphology was evaluated (Fig. $2 B, C)$. Uninjected embryos, and embryos injected into the ventral blastomeres (which do not contribute to brain), served as controls (Fig. 2B; data not shown). Coinjection with lacZ mRNA (a tracer revealing injected cells) and analysis of the $\beta$-gal distribution at stage 35 showed that our targeting of dorsal or ventral tissue was accurate (data not shown). Control tadpoles had intact anterior neural tissue with well formed nostrils, olfactory bulbs/ forebrain, midbrain, and hindbrain (Figure 2Ci; Pratt and Khakhalin, 2013). In contrast, expression of Kv1.5, GlyR +70 $\mathrm{mM} \mathrm{Cl}^{-}$(IVM), or GlyR (IVM) mRNA caused a high incidence of disrupted endogenous brain tissue formation $(33,53$, and $65 \%$, respectively; Fig. $2 B$ ). The most striking phenotype was the absence of nostrils, olfactory bulbs, and forebrain, with severely malformed midbrain (Fig. 2Cii). Occasionally open neural tube 


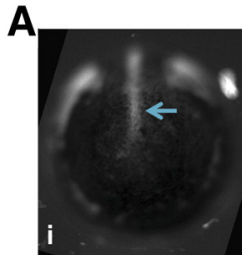

Uninjected

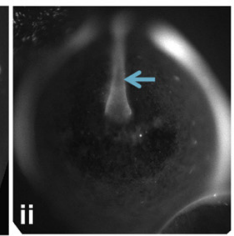

GlyR only

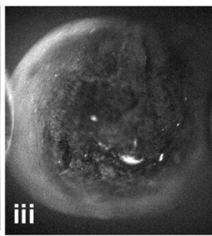

GlyR+IVM

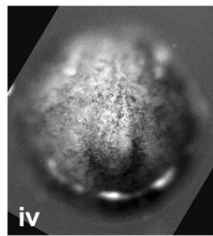

Kv1.5

Too depolarized Too hyperpolarized

Relatively depolarized

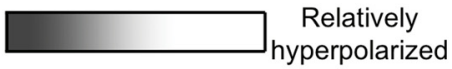

B
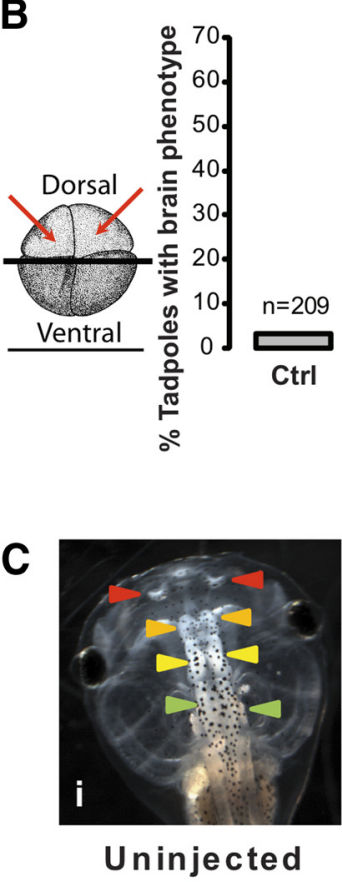

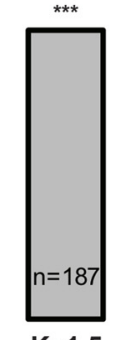

$\mathrm{Kv} 1.5$

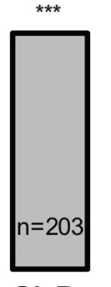

GlyR+

$70 \mathrm{mM} \mathrm{Cl}-$ (IVM)

Too

hyperpolarized
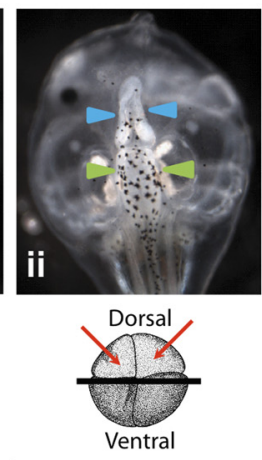
yyperpolarized
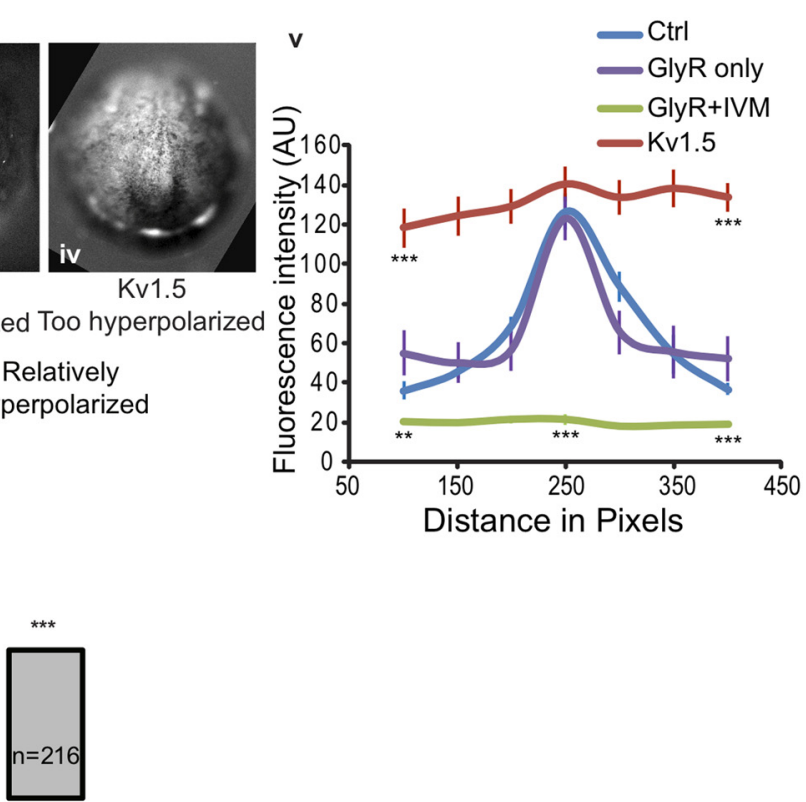

GlyR+

(IVM)

Too

depolarized
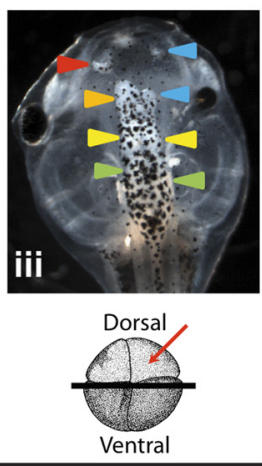

Hyperpolarized - Kv1.5

D
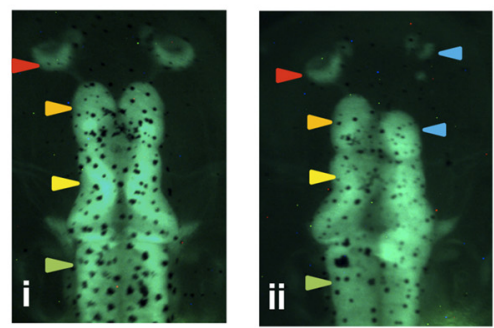

Uninjected Hyperpolarized - Kv1.5

PNTub :: GFP

Figure 2. Local perturbation of $V_{\text {mem }}$ disrupts endogenous brain development. A, CC2-DMPE:DiBAC staining of stage 16 Xenopus control (uninjected) and Kv1.5, GlyR (+IVM), or only GlyRmicroinjected (two dorsal cells at four-cell stage) embryos. Control embryos $(n=28 ; A i)$ and only GlyR $(n=34 ; A i v)$-injected embryos showed characteristic hyperpolarization within the forming neural tube (blue arrow) but the Kv1.5-injected embryo (Aii) shows widespread hyperpolarization $\left[n=24,21\right.$ embryos (87.5\%) show changed $\left.V_{\text {mem }}\right]$ and the GlyR (+IVM, in standard saline) embryo (Aiii) shows widespread depolarization $\left[n=27,18\right.$ embryos (66.7\%) show changed $V_{\text {mem }}$. Av, Fluorescence intensity measurements of CC2-DMPE:DiBAC-stained embryos. One-way ANOVA analysis pixel distance 100, 250, and 400, shows significant difference of CC2-DMPE:DiBAC signal in the Kv1.5 and GlyR + IVM embryos compared with control embryos. Data are represented as mean \pm SEM; ${ }^{* * *} p<0.001$ and ${ }^{* *} p<0.01$. B, Quantification of tadpoles with brain phenotypes upon microinjections of $K v 1.5$ or GlyR $\left(+\mathrm{IVM} \pm 70 \mathrm{~mm} \mathrm{Cl}^{-}\right)$ion channel mRNA in the two dorsal cells (red arrows) of the four-cell Xenopus embryo. A high incidence of malformed brain is observed in dorsal injections compared with uninjected controls. A $\chi^{2}$ analysis showed that the too-hyperpolarized and the too-depolarized embryos were significantly different from the rightly polarized controls. ${ }^{* * *} p<0.001$. C, Four-cell Xenopus embryos were injected (red arrow indicates injected cell). Ci, Stage 45 uninjected control tadpoles show well formed anterior neural tissue with red arrowheads indicating nostrils, orange arrowheads indicating forebrain/olfactory bulbs, yellow arrowheads indicating mid brain, and green arrowheads indicating hindbrain. Cii, Stage 45 tadpole injected with hyperpolarizing channel $K v 1.5$ in both the dorsal cells at the four-cell stage. The green arrowheads indicate the hindbrain, which remains largely unaffected. Blue arrowheads indicate severely malformed midbrain and forebrain. Eyes were also (Figure legend continues.) 
defects were also seen, but these embryos usually did not survive to stage 45. Eye development (which is dependent on proper neural development; Harada et al., 2007; Fuhrmann, 2010; Zuber, 2010) was also affected, resulting in incompletely formed eyes, eyes fused to the brain, and pigmented optic nerves (data not shown) as previously documented (Pai et al., 2012b).

Although bioelectric signals have been previously shown to act across considerable distance in vivo (Brown et al., 1994; Blackiston et al., 2011), the observed highly localized hyperpolarization signal in cells of the forming neural tube suggested a local role in brain development. To test the effective range of influence of the hyperpolarization signal, only one side (one dorsal cell at the four-cell stage) of the embryo was then targeted with $K v 1.5$ mRNA (Fig. 2Ciii,Dii) with the contralateral side as internal control for brain tissue morphology. In anticipation of subtle changes in brain tissue anatomy, we used a transgenic frog line, PNTub-GFP (Marsh-Armstrong et al., 1999; Lin et al., 2012), where GFP expression is driven by the neural tubulin promoter, resulting in tadpoles whose CNS tissue is GFP labeled (gut is autofluorescent in the same spectrum; Fig. 2D; data not shown). This allowed clear visualization of all Xenopus brain structures (nostrils, olfactory bulb/forebrain, midbrain, and hindbrain; Fig. $2 \mathrm{Di}$ ). Although nostrils and the forebrain/olfactory bulb were the most commonly affected, other subtle brain phenotypes were also observed with dorsal injections using these PNTub-GFP embryos. Phenotypes include bulged midbrain, improper junction between midbrain and forebrain, improperly folded midbrain and forebrain, and fused nostrils (data not shown). Only the injected side showed defects in brain tissue formation (malformed nostrils and reduced olfactory bulb/forebrain lobe), whereas the contralateral uninjected side had normal brain tissue development (Fig. 2Ciii,Dii; possible subtle brain-independent phenotypes on the contralateral uninjected side were not monitored). These results suggest that correct $V_{\text {mem }}$ is a crucial part of normal brain patterning and that this signal does not cross the left-right midline.

We independently used two different ion channels ( $K v 1.5$ and $G l y R+I V M+70 \mathrm{mM} \mathrm{Cl}^{-}$) to hyperpolarize because these have no homology at the sequence or structure level, transport totally different ion species, and interact with distinct regulatory molecules. This allowed us to address the functional role of hyperpolarization per se, independently of protein-specific (nonion-related) functions of either channel, or of chemical (not voltage) properties of either potassium or chloride. The major common factor between these two ion channels is their action (hyperpolarization) on changing $V_{\text {mem }}$. That both channels cause the same brain tissue phenotype suggests the involvement of $V_{\text {mem }}$, rather than a channel- or ion-specific role, although additional nonion-related (protein-specific or chemical) possibilities cannot be completely ruled out.

$\leftarrow$

(Figure legend continued.) found to be malformed or absent. Ciii, Stage 45 tadpole that had been injected with hyperpolarizing Kv1.5 in only one dorsal cell of four-cell embryo with the other side as contralateral control. The uninjected side of the embryo shows unaffected nostrils, forebrain, midbrain, and hindbrain (arrowhead colors as in $(i)$. The injected side of the embryo shows misformed nostrils and forebrain/olfactory bulb (blue arrowheads) but unaffected midbrain and hindbrain. $\boldsymbol{D}$, Stage 45 PNTub::GFP transgenic tadpole shows GFP fluorescence in neural tissue (arrowhead colors as in Ci). Gut autofluorescence is also seen as indicated. Di, The uninjected control tadpole shows intact nostrils, forebrain/olfactory bulbs, midbrain, and hindbrain. Dii, Stage 45 tadpoles injected with Kv1.5 ion channel mRNA in one dorsal cell at the four-cell stage, with the contralateral side of the brain as control (as in ciii). Blue arrowheads indicate the malformed nostrils and forebrain/olfactory bulbs regions in the injected tadpole $(n=100)$. Black spots are melanocytes.
Our second hypothesis was that both homogenous upregulation and downregulation of $V_{\text {mem }}$ throughout the tissue would cause brain-patterning defects because the spatial pattern of differential voltage states is important. Indeed, both hyperpolarization $(K v 1.5)$ and depolarization $(G l y R+$ IVM) caused brain malformations. Therefore, we suggest that in brain tissue patterning, as is the case for many developmental signals (bioelectricity and chemical factors like Retinoic Acid, Notch, Sonic hedgehog, Wnt, etc.), it is the correct range and distribution that is key; too much or too little of a tightly regulated instructive signal in key locations both cause phenotypes (Artavanis-Tsakonas et al., 1995; Dolmetsch et al., 1998; Pai et al., 2012b; Hori et al., 2013; Levin, 2013; Tseng and Levin, 2013).These results suggest that the $V_{\text {mem }}$ states within the folding neural plate likely serve as an important endogenous component of normal brain development.

\section{Perturbation of neural $V_{\text {mem }}$ signal disrupts endogenous brain development markers}

Where do $V_{\text {mem }}$ levels function within the hierarchy of known transcriptional regulators of midbrain and forebrain patterning? To assess this, we analyzed the expression of the key transcription factors otx2 (forebrain and midbrain), emx (telencephalon and forebrain), and $b f 1$ (forebrain precursors) in hyperpolarized embryos (Acampora et al., 1995; Li and Joyner, 2001; Muzio and Mallamaci, 2003; Mukhopadhyay et al., 2011). The expression of otx 2 and emx marks the anterior neural plate and these genes are critically involved in the patterning of midbrain (Acampora et al., 1995; Li and Joyner, 2001; Muzio and Mallamaci, 2003; Wendler et al., 2013), while $b f 1$ is an important regulator of forebrain patterning (Bourguignon et al., 1998; Mukhopadhyay et al., 2011). Embryos were injected into one dorsal cell at the four-cell stage with $K v 1.5$ or GlyR $+70 \mathrm{mM} \mathrm{Cl}^{-}$(IVM; both hyperpolarizing conditions) and analyzed at two different stages: $21 / 22$ and 30. The contralateral uninjected side of the same embryo and uninjected embryos were used as controls. Expression of otx2, $b f 1$, and $e m x$ was revealed by in situ hybridization (Fig. $3 A$ ). While the differences are apparent qualitatively, the in situ hybridization signal was also quantified as ratio of control versus injected contralateral sides (Fig. 3A). Injected embryos showed significantly reduced (in both overall area and intensity) expression of otx2, emx, and bf1 (Fig. 3A) in the neural field at both stages $21 / 22$ $(N=9$ of 13,7 of 10 , and 6 of 9 , respectively) and stage $30[N=$ 10 of $14(e m x)$ and 6 of $9(b f 1)]$. The contralateral uninjected side of embryos had normal endogenous levels and patterns of expression compared with uninjected control embryos at both stages $21 / 22$ and 30 (Fig. $3 A$ ). These results suggest that the $V_{\text {mem }}$ signal in the neural plate can function upstream (regulates expression) of ot $x 2$, emx, and $b f 1$ during brain development, although this influence may not be direct and could involve additional intermediate genes.

We next asked whether the effects of $V_{\text {mem }}$ on brain patterning were directly linked to later, brain-specific processes, or a consequence of $V_{\text {mem }}$ effects on the earlier phases of embryonic patterning and thus neural induction. To assess this, we performed in situ hybridization with antisense mRNA for the canonical dorsal markers cerberus and chordin (Fig. 3B). Positive controls illustrating classical changes of neural induction were produced by treating embryos with either the dorsalizing agent $\mathrm{LiCl}$ or the ventralizing agent UV light. Untreated embryos were used as negative controls. Experimental embryos were injected with hyperpolarizing channel $K v 1.5 \mathrm{mRNA}$ into the two dorsal cells at the four-cell stage and raised until stage 30 (Fig. 3Bi-iv). LiCltreated embryos were severely dorsalized, with increased expression 
A

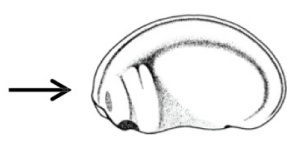

Ctrl

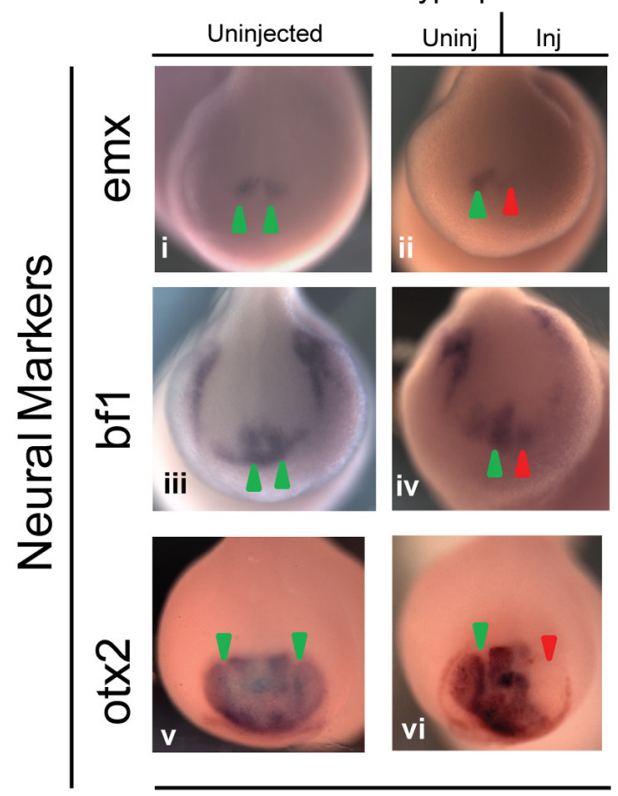

Stage 21/22

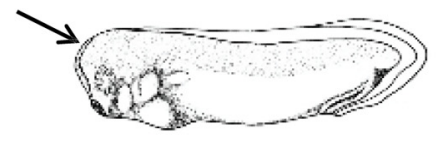

Ctrl Hyperpolarized
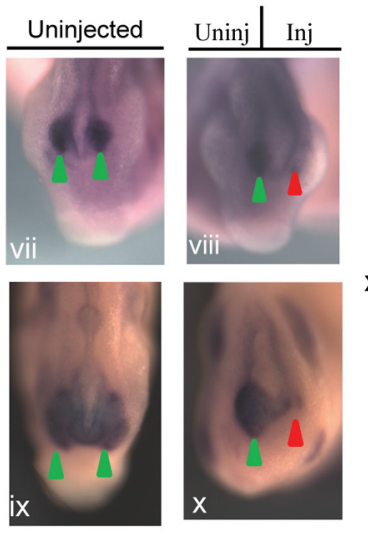

Stage 30

$\triangle$ Normal Signal

$\triangle$ Decreased/absent Signal

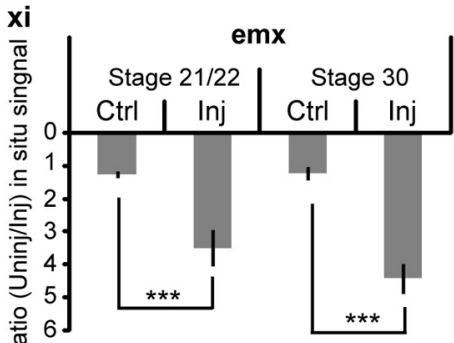

$x i i \frac{\frac{\pi}{2}}{\frac{\pi}{5}}$

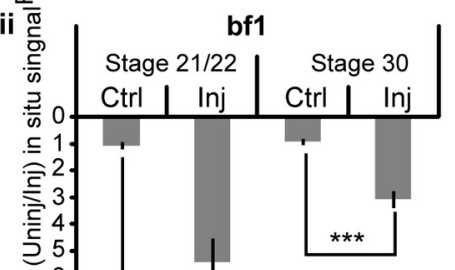

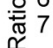

xiii

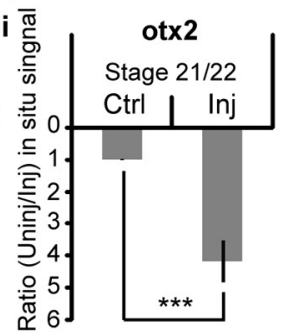

B

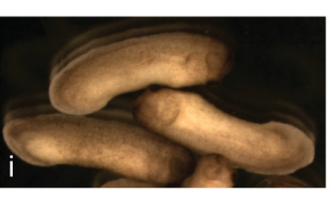

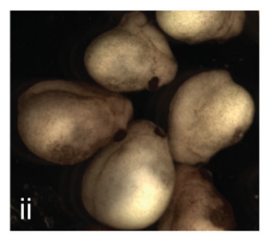

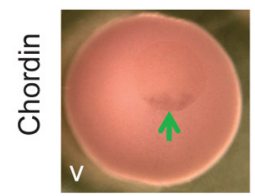

Ctrl

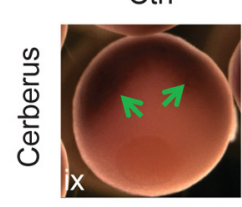

$\mathrm{LiCl}$

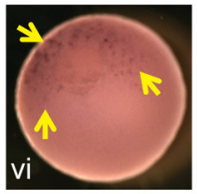

$\mathrm{LiCl}$

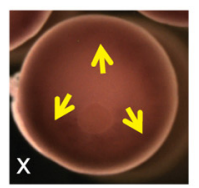

$\mathrm{LiCl}$

UV

UV

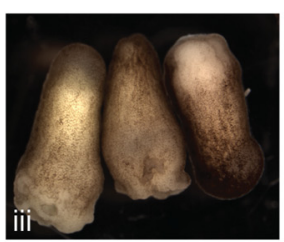

Kv1.5

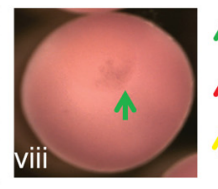

Kv1.5
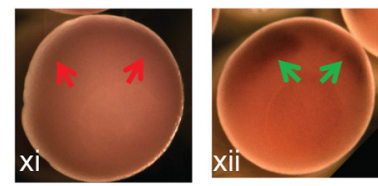

Normal Signal

个 Decreased/absent Signal Increased Signal

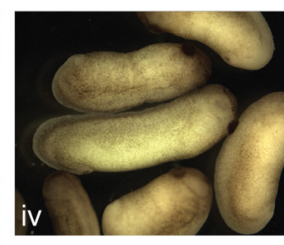

Figure 3. Local perturbation of $V_{\text {mem }}$ signal disrupts endogenous forebrain marker expression during neural development. $A$, Control (Ctrl; uninjected) embryos at the indicated stage (Ai, Aiii, $\boldsymbol{A v}, \boldsymbol{A v i i}$, Aix) and embryos microinjected (Inj) with Kv1.5 mRNA (Aii, Aiv, Avi, Aviii, Ax) in the right dorsal cell at the four-cell stage. In situ hybridization for emx (Ai, Aii [ $n=7$ of 10], Avii, Aviii [ $[n=$ 10 of 14]), bf1 (Aiiii, Aiv [ $n=6$ of 9], $A i x, A x[n=6$ of 9]), and otx2 (Av, Avi $[n=9$ of 13]) show a significantly decreased or missing expression (red arrowheads) of emx, bf1, and otx2 only on the injected side of the embryos, while expression on the uninjected (Uninj) side is intact (green arrowheads). Quantification of the in situ signal (Axi-xiii) as ratio of the signal intensity for uninjected verses its contralateral injected side for emx (Axi), bf1 (Axii), and otx2 (Axiii) show a significant change in the in situ signal for these probes upon Kv1.5 mRNA injection. The data are represented as mean \pm SEM ( $n>8$ for each). The data are analyzed via $t$ test. ${ }^{* * *} p<0.001$. $\boldsymbol{B}$, Control (untreated) embryos (Bi, Bv, Bix), embryos treated with LiCl ( $0.2 \mathrm{~m}$ for $10 \mathrm{~min}$ at 32 -cell stage; $\left.\boldsymbol{B i i}, \boldsymbol{B} \boldsymbol{B i}, \boldsymbol{B} \boldsymbol{B}\right)$, UV light (75 s; Biii, Bvii, Bxi) and microinjected with Kv1.5 mRNA in the two dorsal cells at four-cell stage (Biv, Bviii, Bxii). Phase contrast images (Bi-iv) of embryos at stage 30 show that LiCl treatment (Bii) dorsalizes the embryos with a majority of dorsal tissue and lack of ventral tissue development, while UV treatment (Biii) ventralizes the embryos with increased ventral tissue specification and lack of dorsal tissue development as compared with control embryos (Bi), which show correctly balanced development of dorsal and ventral tissues. Kv1.5-injected embryos (Biv) appear normal similar to control embryos with balanced development of dorsal and ventral tissues. In situ hybridization for dorsalization markers chordin (Bv-viii) and cerberus (Bix-xii) show

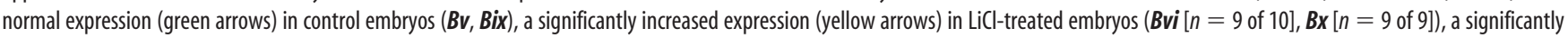
decreased expression (red arrow) in UV-treated embryos (Bvii [ $n=14$ of 15], Bxi $[n=11$ of 11]), and relatively unchanged expression (green arrows) in Kv1.5-injected embryos (Bviii $[n=20$ of 20], Bxii [ $[=18$ of 18]) compared with control embryos. 

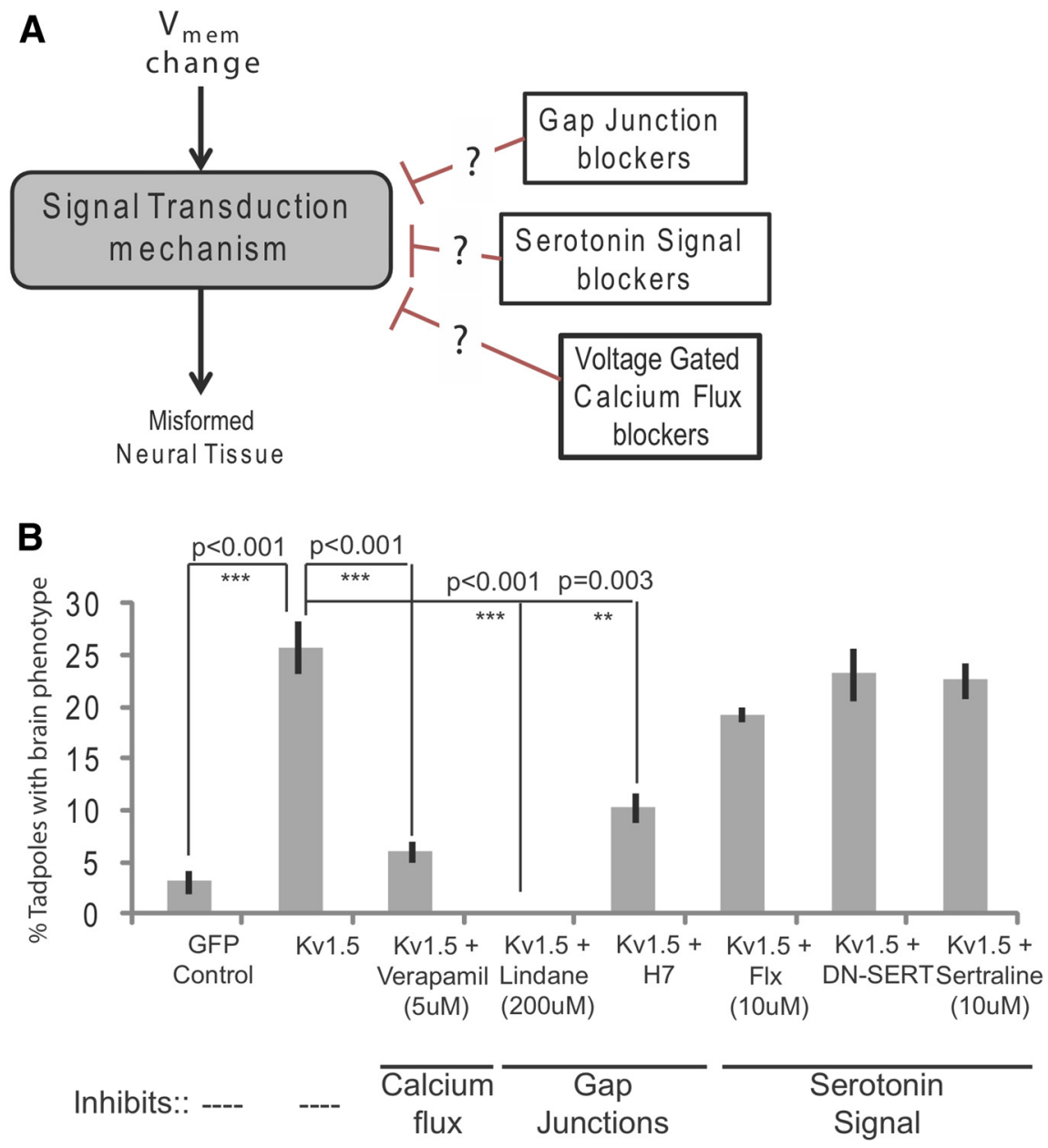

Figure 4. The $V_{\text {mem }}$ signal is transduced via $\mathrm{Ca}^{2+}$ and $G J . A$, Schematic of the logic behind the suppression screen to test known candidate mechanisms for transduction of $V_{\text {mem }}$ change to malformed brain tissue phenotype in tadpoles: $G$, serotonin signaling, and calcium influx. B, Quantification of tadpoles with malformed brain phenotype in control (GFP-injected) and Kv1.5microinjected (dorsal two blastomeres at four-cell stage) embryos with or without the indicated inhibitors. A high incidence of malformed brain phenotype is seen in Kv1.5-microinjected embryos and this effect of $K v 1.5$ is prevented by verapamil (a blocker of voltage-gated calcium channels, stages 10-30), Lindane (a blocker of GJC among cells, stages 10-30), and H7 (a chimeric dominant-negative connexin that blocks $\mathrm{GJ}$ ) but not by fluoxetine (FIx) or sertraline (chemical blockers of the serotonin transporter, stages 10-30) or dominant-negative SERT (DN-SERT) mutant (molecular blocker of serotonin transport). A one-way ANOVA ( $n=3$ experiments) analysis with post hoc test showed significant variance among the groups, with Kv1.5 significantly different from control, Kv1.5 + verapamil, Kv1.5 + Lindane, and Kv1.5 + H7. ${ }^{* * *} p<0.001,{ }^{* *} p<0.01$.

of $\operatorname{chordin}(N=9$ of 10$)$ and cerberus $(N=9$ of 9 ; Fig. 3Bii,vi,x), and a majority formed only dorsal tissue (head, spine, and mouth; Fig. 3Bii). UV-treated embryos were severely ventralized with significantly reduced expression of chordin $(N=14$ of 15$)$ and cerberus $(N=11$ of 11 ; Fig. 3 Biii, vii, xi), and a majority formed only ventral tissue (gut; Fig. 3Biii). In contrast, Kv1.5-injected embryos showed control levels and pattern of chordin $(N=20$ of 20) and cerberus $(N=18$ of 18 ) expression (Fig. 3Bviii,xii) and developed normal ventral and dorsal tissues similar to control embryos (Fig. 3Biv). These results do not support effects of $V_{\text {mem }}$ change on the initial phase of large-scale embryonic dorsoventral axis patterning before neural induction, and suggest that the observed voltage regulation of $\operatorname{ot} x 2$, emx , and $b f 1$ is a later event associated with brain patterning.

\section{$V_{\text {mem }}$ effects on brain development are transduced by $\mathrm{Ca}^{2+}$ channels and GJs}

How are changes in $V_{\text {mem }}$ transduced into downstream transcriptional and cellular behavior changes during brain development? To assess this, we performed a suppression test, targeting candidate mechanisms that have been previously shown to convert $V_{\text {mem }}$ changes into transcriptional responses in other contexts (Levin and Stevenson, 2012; Adams and Levin, 2013; Levin, 2014; Pai and Levin, 2014). As before, injection of hyperpolarizing Kv1.5 mRNA into the two dorsal cells of four-cell embryos was used to disturb the later endogenous neural induction $V_{\text {mem }}$ pattern (Fig. 2). Then, each of several targets known to be able to connect $V_{\text {mem }}$ changes to downstream signaling steps (Adams and Levin, 2013) was blocked, one at a time, to determine which one would suppress the Kv1.5 (hyperpolarization)-mediated brain defects (Fig. 4A). Our loss-of-function screen tested pathways for the ability to suppress defects induced by external (experimental) voltage change; all of the reagents were titered to levels that did not, on their own, disrupt endogenous brain patterning in control embryos, to avoid any confounds arising from toxic or teratological effects. Pharmacological blockade was performed during stages 10-30: these are the key stages for brain development, and thus this is the time period during which the $V_{\text {mem }}$-dependent events must be targeted to attempt to rescue brain development.

Blocking serotonergic signaling via inhibition of the serotonin transporter by chemical blockers (fluoxetine and sertraline; Fukumoto et al., 2005b; Blackiston et al., 2011) or by expression of a dominantnegative SERT mutant protein (Barker et al., 1999; Fukumoto et al., 2005b) did not suppress the effect of $K v 1.5$-mediated hyperpolarization on brain development (Fig. 4B), though all of these reagents have been shown to efficiently perturb serotonin signaling in Xenopus (Barker et al., 1999; Quick, 2003; Fukumoto et al., 2005b; Blackiston et al., 2011; Linder et al., 2014). In contrast, blocking VGCCs (using verapamil), or blocking GJs (using Lindane, a chemical blocker, or mRNA encoding H7, a chimeric dominant-negative connexin construct that inhibits GJ; Paul et al., 1995; Levin and Mercola, 1998) almost completely suppressed the effect of Kv1.5mediated hyperpolarization on brain development (Fig. $4 B$; three experimental repeats, one-way ANOVA, $p<0.001$ with post hoc test). These results suggest that hyperpolarization is likely transduced into downstream cascades via mechanisms involving $\mathrm{Ca}^{2+}$ flux and GJ-mediated signaling. These data are consistent with the increased understanding of $\mathrm{Ca}^{2+}$ as a central player in the induction of neural fate (Moreau and Leclerc, 2004; Leclerc et al., 2006; Aruga and Mikoshiba, 2011), but do not exclude the involvement of additional transduction mechanisms.

\section{Reinforcing brain-appropriate $V_{\text {mem }}$ state rescues active Notch-induced brain defects}

We next asked whether reinforcing the brain-appropriate $V_{\text {mem }}$ state could be used to repair brain defects induced by disruption 


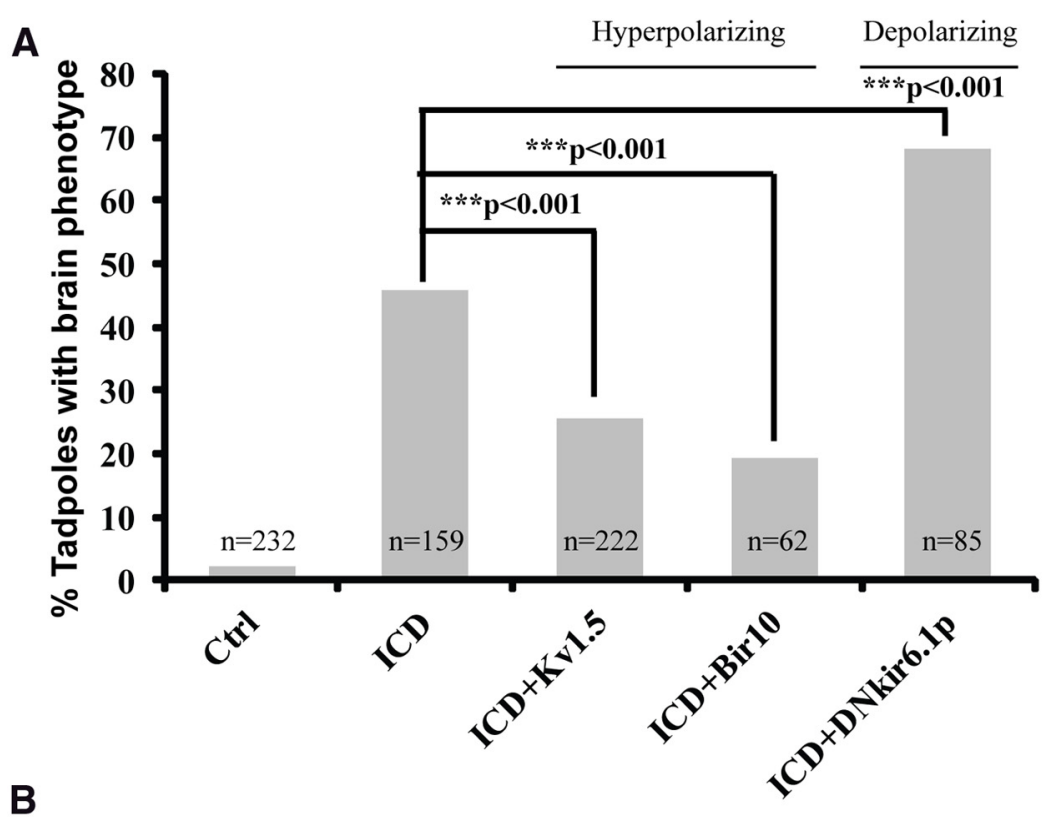

Control

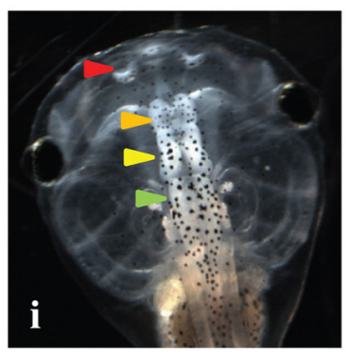

C

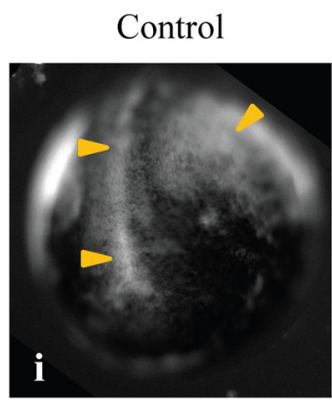

-

Relatively

depolarized
ICD

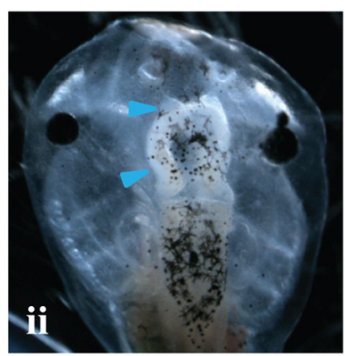

ICD

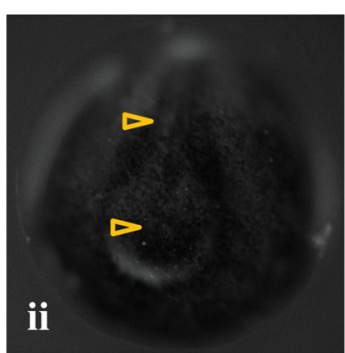

Relatively

hyperpolarized
IC D +Bir 10

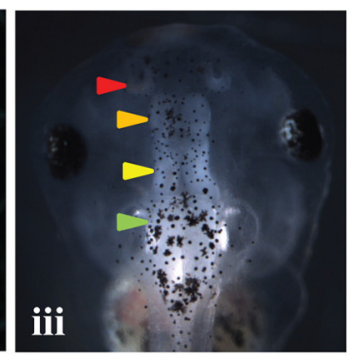

D

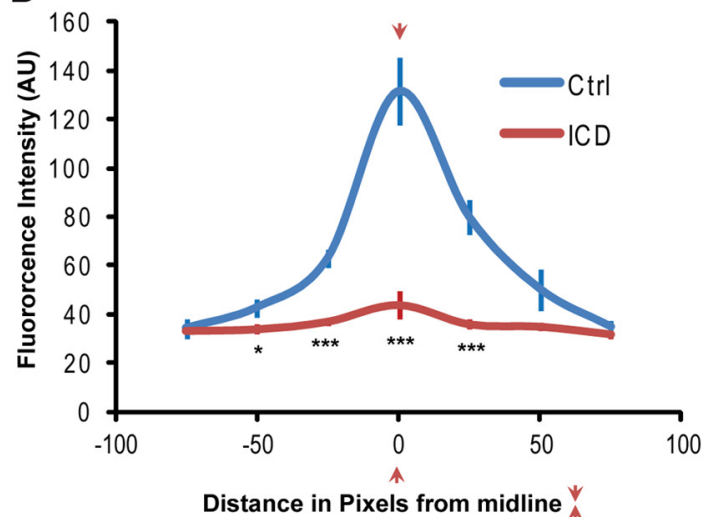

Figure 5. Notch ICD-induced brain mispatterning can be rescued by $V_{\text {mem }}$ modulation. $A$, Quantification of tadpoles with malformed brain phenotype in control (Ctrl; uninjected) embryos and embryos microinjected with a constitutively active notch ICD mRNA (in the dorsal two blastomeres at four-cell stage) alone or in combination with Kv1.5 or Bir10 or dominant-negative Kir6.1p mRNA. As expected (see text), misexpression of Notch ICD alone results in a malformed brain phenotype. Remarkably, hyperpolarizing mRNAs Kv1.5 and Bir10 significantly rescue this effect, while depolarizing channel mRNA (DNKir6.1p) increases the number of tadpoles with malformed brains. A $\chi^{2}$ analysis showed that the Notch ICD group is significantly different from the other (Ctrl, Notch $I C D+K v 1.5$, Notch ICD + Bir10, and Notch ICD + DNKir6.1p) groups. ${ }^{* *} p<0.001$. B, Four-cell Xenopus embryos were microinjected with the indicated constructs in two dorsal cells. Bi, Stage 45 control (uninjected) embryos show well formed anterior neural tissue including nostrils, forebrain/olfactory bulbs, midbrain, and hindbrain (arrowhead colors as in Fig. $2(i)$. Bii, Stage 45 tadpoles injected with constitutively active notch ICD showed severely malformed neural patterning with the forebrain almost absent and a severely mispatterned midbrain (blue arrowheads). Biii, Stage 45 tadpole injected with both Notch ICD and hyperpolarizing Bir10 ion channel showed significant restoration of neural patterning with intact nostrils and distinct forebrain, midbrain, and hindbrain (arrowhead colors as in Fig. 2Ci). Biv, Stage 45 tadpole injected with both Notch ICD and depolarizing dominant-negative DNKir6.1p channel mRNA shows severely malformed neural tissues and eye patterning with nostrils and forebrain/olfactory bulbs absent and mispatterned midbrain (blue arrowheads). C, Imaging of resting potentials during brain development reveals that Notch ICD misexpression perturbs the normal hyperpolarization patterns required for brain patterning. Fluorescent voltage-sensitive dye (CC2-DMPE:DiBAC) staining of stage 16 Xenopus control (uninjected) embryos (Ci $[n=12])$ and embryos microinjected with Notch ICD in two dorsal cells at four-cell stage (Cii $[n=10])$. Control embryos show the expected (Fig. 1) hyperpolarization in the forming neural tube as well as in the lateral region of the embryo (solid orange arrowheads), while the Notch ICD-injected embryos are depolarized and fail to show the characteristic hyperpolarization signal (empty orange arrowheads) and develop major neural tissue and eye-patterning defects if grown to stage 45 (see $\boldsymbol{B})$. D. Fluorescence intensity measurements of CC2-DMPE:DiBAC-stained embryos. One-way ANOVA analysis shows significant difference of CC2-DMPE:DiBAC signal in the Notch ICD-injected embryos $(n=10)$ compared with control (uninjected) embryos $(n=12)$. Data are represented as mean \pm SEM; ${ }^{* * *} p<0.001$ and ${ }^{*} p<0.05$. 


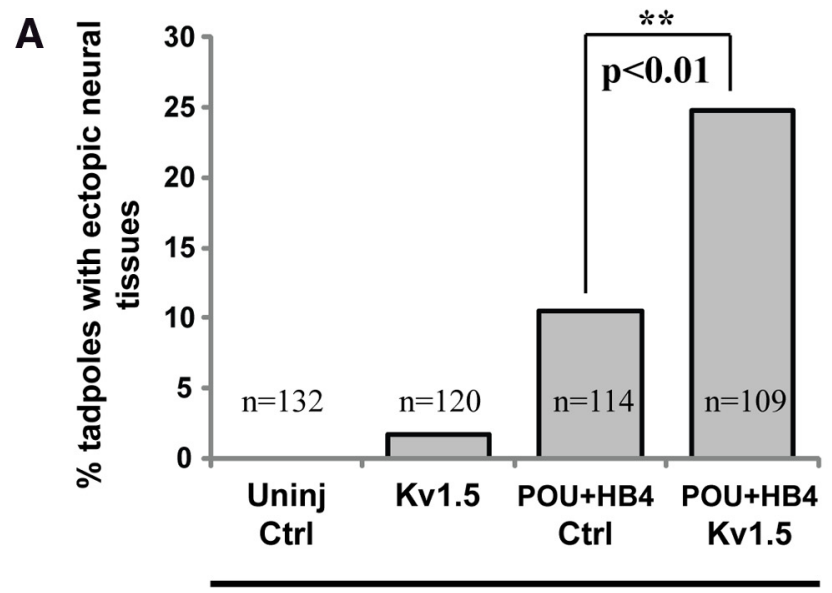

B Control
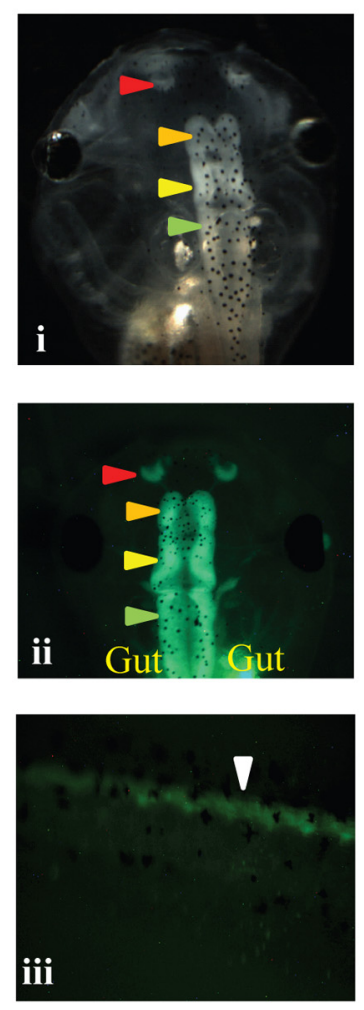

POU+HB4+Kv1.5
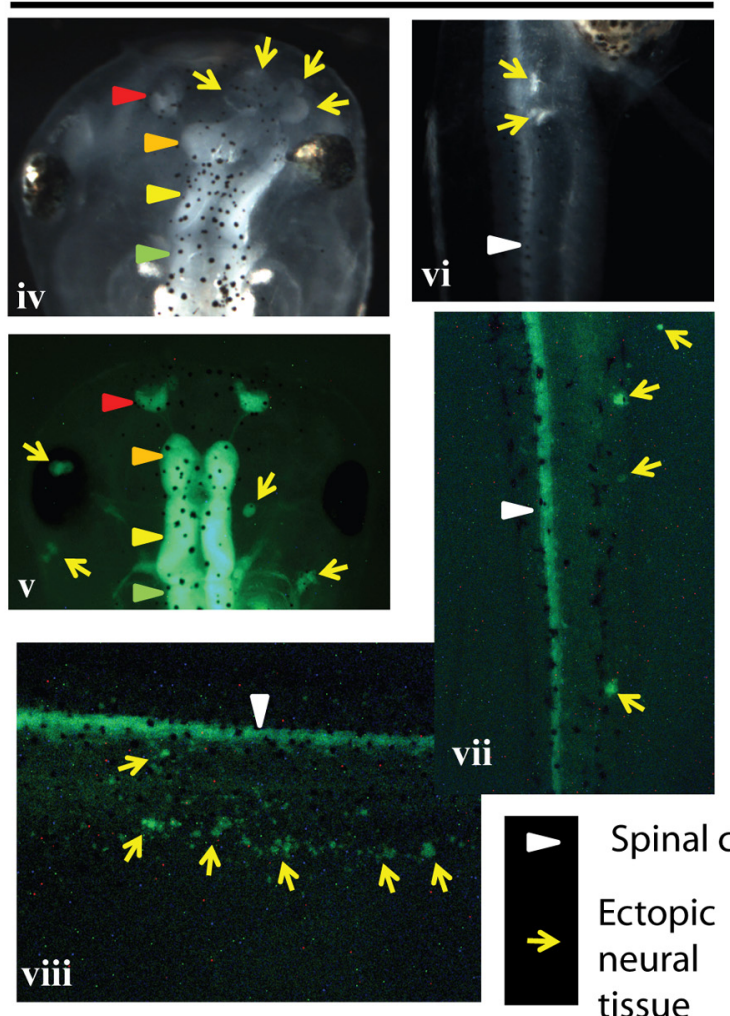

Spinal cord

Ectopic

neural

tissue

\section{PNTub::GFP}

Figure 6. $\quad V_{\text {mem }}$ modulation potentiates ability of reprogramming factors to induce ectopic neural tissues. $A$, Quantification of tadpoles with ectopic neural tissue in control embryos (uninjected; Uninj) and embryos microinjected with POU + HB4 mRNA in both cells at the two-cell stage. Coinjection with the hyperpolarizing Kv1.5 channels caused a significant increase in the number of tadpoles with ectopic neural tissue compared with $P O U+H B 4$-only controls. $A \chi^{2}$ analysis showed that the $P O U+H B$-only controls are significantly different fromPOU + HB4 + Kv1.5. ${ }^{* *} p<0.01$. B, Stage 45 PNTub::GFP transgenic tadpoles (Bi-viii). Bi, Biv, and Bviare bright-field images. Bii, Biii, Bv, Bvii, and Bviiiiare GFP fluorescence. Control (uninjected) embryos (Bi-iii) show well patterned nostrils, forebrain/olfactory bulbs, midbrain, hindbrain (arrowhead colors same as Fig. 2Ci), and spinal cord (Biii; white arrowheads). Tadpoles injected with POU + HB4 + hyperpolarizing Kv1.5 (Biv-viii) showed brain tissue that was highly expanded anteriorly (Biv; yellow arrows), noticeable amounts of ectopic neural tissue in the head unattached to the brain ( $B \boldsymbol{V}$; yellow arrows), and noticeable ectopic neural tissue in the tail (Bvi- $\mathbf{v i i i}$; yellow arrows) away from the spinal cord (white arrowhead).

of canonical biochemical pathways. We used mRNA encoding a constitutively active Notch ICD (Beck et al., 2001; Beck and Slack, 2002), a powerful endogenous regulator of neural patterning (Campos-Ortega, 1995; Hori et al., 2013). Notch ICD mRNA was titrated to a dose that causes brain deformities without disrupting other tissues and organs. The embryos were injected in the two dorsal cells at four-cell stage and were either left untreated or coinjected with either hyperpolarizing channel mRNAs (Kv1.5 or Bir10) or depolarizing channel mRNA (dominant-negative Kir6.1-DNKir6.1p). The tadpoles were scored for their brain patterning and morphology at stage 45 .

Notch ICD mRNA injections caused a significantly elevated incidence of malformed brains ( $\sim 46 \%$; Fig. $5 A$ ), compared with uninjected controls. Severe anterior brain morphology defects including loss of nostrils (data not shown), near complete loss of forebrain/olfactory bulbs, and malformed midbrain and eyes were observed (Fig. 5Bi,ii). To determine whether Notch ICD expression causes any effect on the endogenous $V_{\text {mem }}$ pattern, Notch ICD-injected embryos were analyzed at stage 16 using CC2-DMPE: DiBAC voltage reporter dye system (Fig. $5 C, D)$. Unlike controls, the Notch ICDinjected embryos exhibited significant depolarization and a loss of the characteristic hyperpolarization $V_{\text {mem }}$ pattern in the neural plate. It is not yet known whether depolarization of neural fated cells in Notch ICD-injected embryos is due to a direct effect of Notch ICD on $V_{\text {mem }}$ or an indirect effect by switching the fate of injected cells to that of surrounding non-neural (depolarized $V_{\text {mem }}$ ) cells. Nonetheless, our data suggest that Notch signaling is capable of (directly or indirectly) regulating the bioelectric profile of cells during development. Understanding this interaction between notch and $V_{\text {mem }}$ signals remains an active area of investigation.

Coinjection of Notch ICD, which depolarizes cells, with the depolarizing DNKir6.1p channel significantly increased the number of tadpoles with brain deformities $(\sim 68 \%)$ and the severity of brain mispatterning (absence of eyes, nostrils, forebrain/olfactory bulbs, and malformed midbrain and hindbrain) compared with Notch ICD alone (Fig. $5 A, B i v)$. These tadpoles also had severely mispatterned or absent eye development. Having seen that depolarizing channels exacerbate the effect of Notch ICD, we next tested whether hyperpolarizing channels could rescue the brain morphology defects induced by Notch ICD. Interestingly, coinjection of hyperpolarizing channel (Kv1.5 or Bir10) mRNA resulted in partial rescue of the phenotype induced by Notch ICD with significant decrease in the number of tadpoles with brain phenotypes 
( $\sim 26$ and $\sim 19 \%$, respectively; Fig. 5A). These rescued tadpoles showed brain morphology quite similar to that of controls with distinct nostrils, well formed forebrain/ olfactory bulb, midbrain, and hindbrain (Fig. 5Biii). Based on the additive nature of the depolarizing effect, and the rescue via hyperpolarization, we suggest that Notch $I C D$ induces defects by (directly or indirectly) modifying endogenous patterns of $V_{\text {mem}}$. Our data suggest considerable cross talk between Notch and $V_{\text {mem }}$ levels, and show that enforcing correct (close to endogenous) $V_{\text {mem }}$ patterns can rescue brain mispatterning defects. These results strongly support the causal, instructive role of bioelectrical signaling during brain development and establish a link between $V_{\text {mem }}$, a biophysical parameter, and well known chemical-genetic pathways involved in brain patterning.

Perturbation of $V_{\text {mem }}$ is sufficient to induce ectopic neural tissue outside the neural field

The results thus far indicated that correct distributions of $V_{\text {mem }}$ patterns are necessary for the proper development of the brain. We next asked whether these $V_{\text {mem }}$ patterns may also be sufficient to induce neural tissues by hyperpolarizing the $V_{\text {mem }}$ of cells outside the canonical neural induction field. While testing the role of endogenous $V_{\text {mem }}$ signals in neural tissue patterning (Figs. 1, 2; data not shown), we observed that some (5-10\%) PNTub:GFP transgenic embryos injected with Kv1.5 mRNA showed the presence of ectopic neural tissue (data not shown). Injection in all blastomeres at the four-cell stage yielded a similar percentage of tadpoles with ectopic neural tissues detected in both head and tail regions. This revealed that production of neural tissues can be triggered outside of the classical anterior neural field by targeted changes of $V_{\text {mem }}$.

To increase the efficiency of this gainof-function effect of $V_{\text {mem }}$ in the induction of ectopic neural tissue, we probed the possible synergy between cell reprogramming factors and $V_{\text {mem }}$ in vivo. We attempted to make cells more susceptible to bioelectric reprogramming of fate by coinjecting mRNA encoding reprogramming factors (POU-Oct4 homolog and HB4; Snir et al., 2006; Jullien et al., 2010). Injection of reprogramming factors mRNA

$(P O U+H B 4)$ alone was used as control. The $(P O U+H B 4)$ mRNA injections showed a baseline level $(\sim 10 \%)$ of ectopic neural tissue induction (Fig. 6A). Strikingly, injection of Kv1.5 (hyperpolarizing) ion channel mRNA (plus reprogramming factors) in both the cells at two-cell stage (for distribution into random
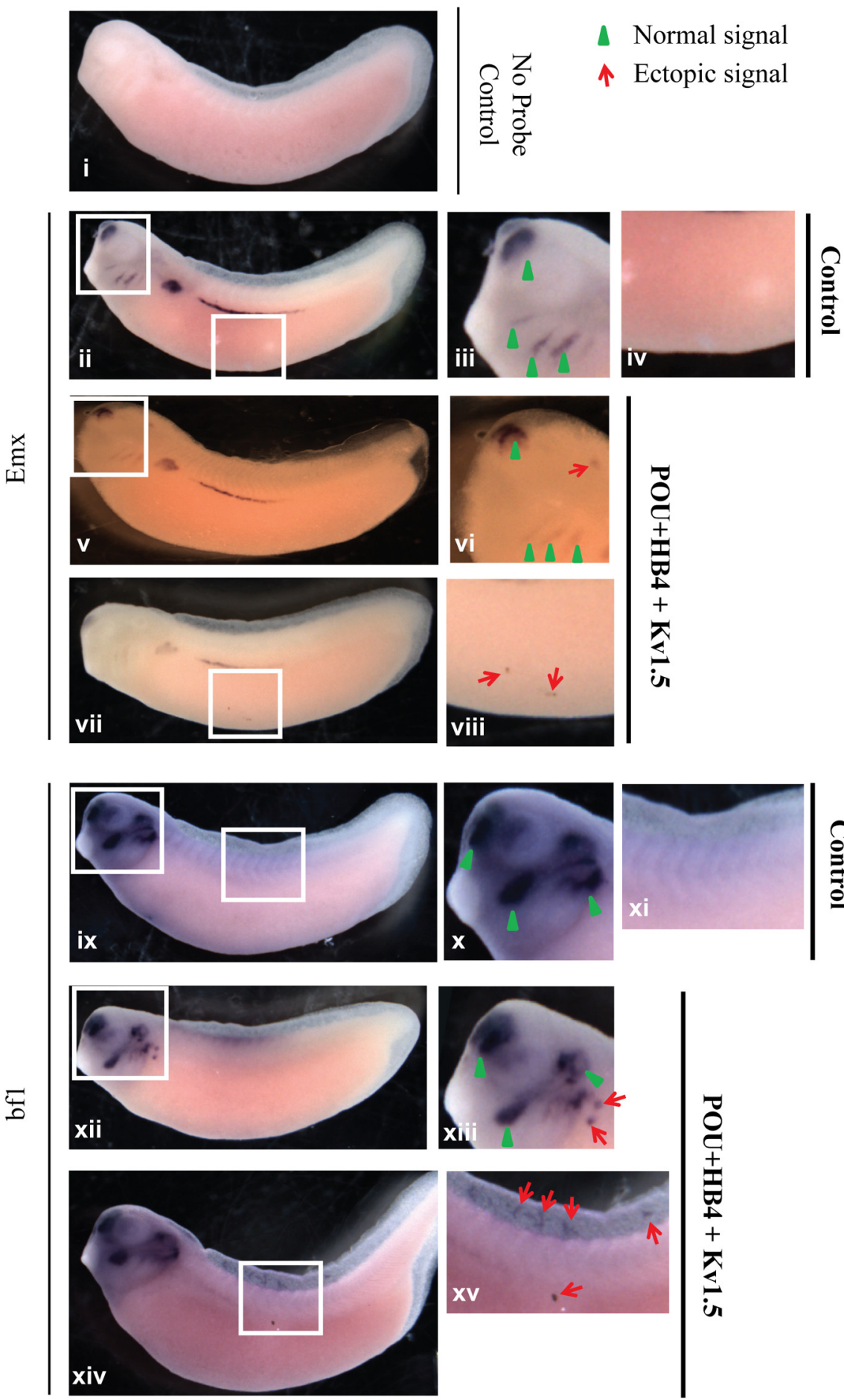

Figure 7. Identity of ectopic neural tissue induced by $V_{\text {mem }}$ modulation was confirmed by in situ hybridization for developing brain-tissue markers. In situ hybridization for forebrain markers emx (ii-viii) and bf1 (ix-xv) of stage 30 control embryos (i-iv $[n=7], \boldsymbol{i x}-\mathbf{x i}[n=11])$ and embryos microinjected (both cells at two-cell stage) with POU + HB4 + Kv1.5 ion channel mRNA $(\boldsymbol{v}-\mathbf{x v})$ [emx: $n=8$ of 15; bf1: $n=6$ of 12]. The areas marked by white squares in $\mathbf{i i}, \boldsymbol{v}, \boldsymbol{v i i}, \mathbf{i x}, \mathbf{x i i}$, and $\mathbf{x i v}$ are expanded in iii, iv, $\boldsymbol{v i}, \boldsymbol{v i i i}, \boldsymbol{x}, \boldsymbol{x i}, \boldsymbol{x i i i}$, and $\boldsymbol{x} \boldsymbol{v}$, respectively. Red arrows mark ectopic expression and green arrowheads mark the endogenous normal signal; especially striking was the appearance of brain marker-positive tissues in the flank and mid-body dorsal fin (xv; red arrows).

tissues) resulted in a more than twofold increase in the number of tadpoles with ectopic neural tissues ( $\sim 25 \%$, respectively; Fig. 6 A) suggesting a synergistic effect. Compared with controls where the GFP signal was only seen specifically in well formed neural tissue (brain and spinal cord; Fig. $6 B$ ), the Kv1.5 mRNA-injected embryos showed regions of the brain that hyperexpanded into other 
A

Kv1.5 - Magenta-Gal

in situ marker

POU+HB4 + Kv1.5 - Magenta Gal
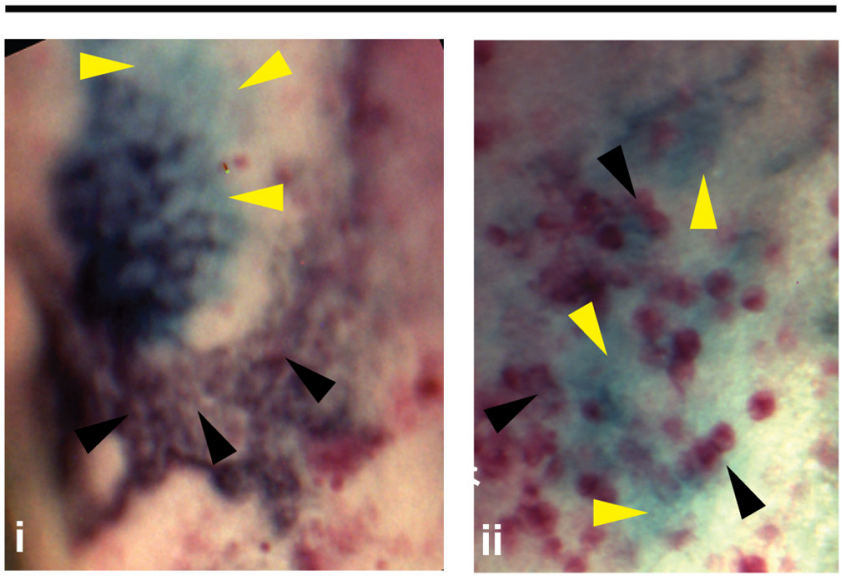

bf1

Stage 30

B POU+HB4 + Kv1.5 - EGFP
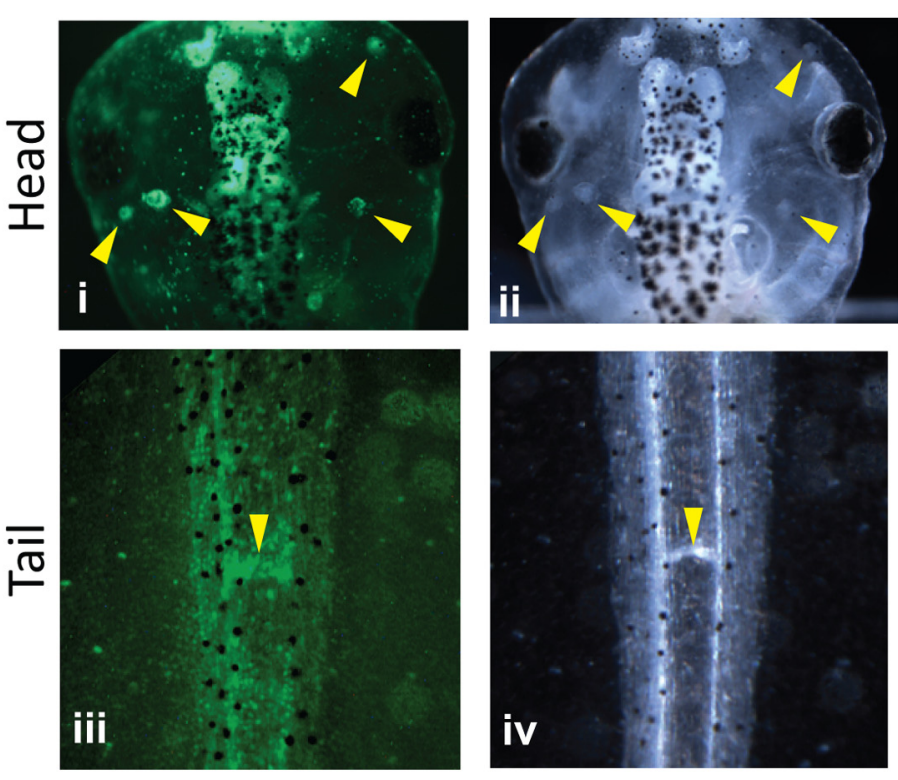

\section{Stage 45}

Kv1.5 hyperpolarizing channel ectopic tissue
C

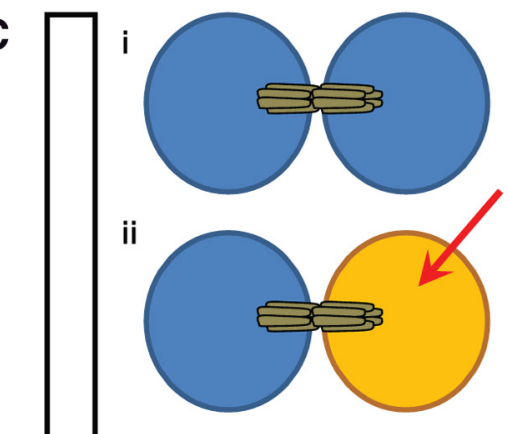

iii

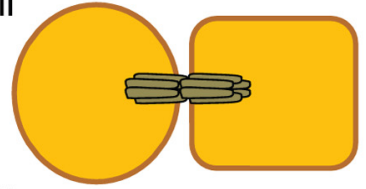

iv
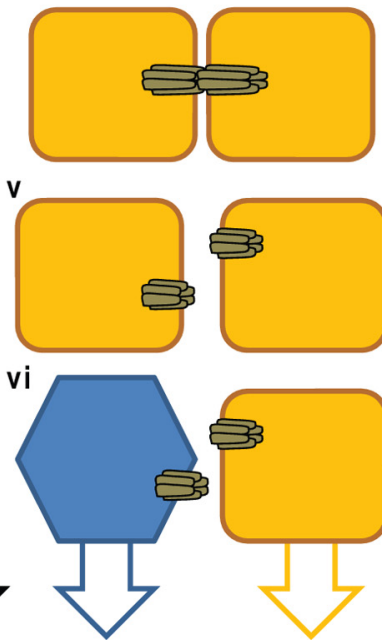

Non-Neural Neural

Tissue Tissue

Connected gap

Junction channel

Unconnected gap

Junction channel

$\leftarrow$ Ion channel injection

Early embryonic cells

Changed $V_{\text {mem }}$ cells

Neural fate cells

Non-Neural fate cells

Figure 8. Ectopic neural tissue induction by $V_{\text {mem }}$ is local but initially not cell autonomous. $A$, In situ hybridization for forebrain markers emx (Ai) and bf1 (Aii; blue) of stage 30 embryos that were microinjected (both cells at two-cell stage) with POU + HB4 + Kv1.5- $\beta$-galactosidase mRNA (red). $\beta$-Galactosidase stain was developed using Magenta-Gal (red/magenta) substrate. At this stage Magenta-Gal signal and emx/bf1 in situ signal overlap with each other, although not perfectly; especially notable are regions where ectopic blue signal (yellow arrowheads; neural marker expression) is next to, but not overlapping with, the misexpressed ion channel (black arrowheads; Magenta-Gal), indicating that not only hyperpolarized cells but also their neighbors are initially driven to turn on neural markers. B, A typical stage 45 tadpole that had been microinjected with POU + HB4 + Kv1.5-EGFP shows that by this stage, ectopic neural tissues induced in the head (Bi, Bii) and tail (Biii, Biv; yellow arrows) are always positive for the EGFP signal indicating hyperpolarizing ion channel expression (this was true in $100 \%$ of embryos examined [ $n=20]$ ). Thus, (Figure legend continues.) 
areas of the head (Fig. 6Biv). Distinct ectopic neural tissue unattached to the endogenous brain was also observed in the head region (Fig. 6Bv). A unique aspect of this phenotype was the frequent presence of punctuate ectopic neural tissues distinctly separate from the spinal cord in the tail of injected tadpoles, which is well outside the anterior neural fields (Fig. 6Bvi-viii).

To verify that the ectopic tissues were indeed brain, embryos injected with reprogramming mRNA $(P O U+H B 4)$ and $K v 1.5$ were analyzed at stage 30 by in situ hybridization for expression of the anterior brain (particularly forebrain neural precursors) markers bf1 and emx (Muzio and Mallamaci, 2003; Eagleson and Theisen, 2008; Mukhopadhyay et al., 2011). While control embryos did not show any ectopic expression of $b f 1(n=11)$ or emx $(n=7)$, the injected embryos showed numerous ectopic foci (average of $\sim 3$ for $b f 1, \sim 2$ for $e m x$ ) of $b f 1$ ( 6 of 12 embryos) and emx (8 of 15 embryos; Fig. 7 ) in the head, tail, and ventral regions. We further validated the ectopic foci by immunohistochemistry for neural marker Sox2 and NCAM (Balak et al., 1987; Suh et al., 2007; Gaete et al., 2012; data not shown). These results suggest considerable synergy between the reprogramming factors and bioelectric state in determining brain identity for diverse embryonic regions.

\section{De novo induction of neural tissue by $V_{\text {mem }}$ occurs in a local/ cell autonomous manner}

Do only the injected cells undergo respecification and acquire neural fate in a cell-autonomous manner, or do they induce their surrounding cells to switch to neural fate (noncell-autonomous signaling)? To assess this, we injected reprogramming factor $(P O U+H B 4)$ mRNA plus (hyperpolarizing) Kv1.5 mRNA fused to $L a c Z$, which allowed lineage tracing of the cells that have received the injected ion channel mRNA. The embryos were injected in both cells at the two-cell stage and then analyzed at stage 30. The LacZ stain was developed using Magenta-Gal substrate to mark the cells misexpressing the ion channel, and the embryos were then analyzed by in situ hybridization for ectopic expression of neural markers $b f 1$ and $e m x$ (indicates the ectopic neural tissue induced; Fig. 8A). Many areas of ectopic $b f 1$ and $e m x$ expression were found to colocalize with cells/areas staining for Magenta-

(Figure legend continued.) by stage 45 , any neighboring cells that were not hyperpolarized have turned off the aberrant neural markers, and only cells that were expressing the channel remain and form ectopic brain. Conversely, at both stages, we observed expression of the hyperpolarizing channel in some regions in which it was not sufficient to induce neural markers or ectopic brain. $C$, A model for de novo neural tissue induction by $V_{\text {mem }}$ change was formulated to explain the local but initially not cell-autonomous misexpression of neural fate induced by hyperpolarization. This model is based on cells sharing their resting potential through GJs. Such electrical coupling of cells has been documented during neural induction and within the developing neural plate cells (Properzi et al., 2013) with the transfer of $V_{\text {mem }}$ signals occurring to the surrounding cells through these GJ couplings (Blackshaw and Warner, 1976; Shi and Borgens, 1995). As cell fields become partitioned into more finely defined regions with developmental age, large areas of $G J$ connections are progressively shut down to isolate specific groups of cells with different fates and to insulate such isopotential groups from the long-range signals (Warner, 1985, Fig. 8C). Early pluripotent embryonic cells are connected by GJ to form isopotential cell clusters with respect to $V_{\text {mem }}(\boldsymbol{C} i)$. Introduction of an ion channel in one cell results in the hyperpolarization of the $V_{\text {mem }}$ of that cell (Cii). As the cell adopts a neural fate and turns on expression of neural markers (Ciii), GJs spread this hyperpolarization to coupled neighbors, causing them also to express the observed ectopic neural markers even though they were not injected with the channel (Civ). As embryonic development proceeds, the tissues become progressively more subdivided with respect to gap junctional connections ( $\boldsymbol{C}$ ). As coupling is reduced, the uninjected cells lose the temporarily hyperpolarized $V_{\text {mem }}$ and then revert back to their original non-neural fate, whereas the injected cells retain their new/changed $V_{\text {mem }}$ giving rise to de novo neural tissues detected at much later stages (Cvi).
Gal (Fig. 8A, black arrowheads). Importantly, however, ectopic areas with $b f 1$ and emx signal that were not overlapping with Magenta-Gal were also observed (Fig. 8A, yellow arrowheads). These results suggest that at stage 30 the induction of ectopic neural tissue was not entirely cell autonomous, and that hyperpolarized cells could recruit some uninjected neighbors to inappropriately express brain markers.

To assess these findings in later stage 45 tadpole (where clearly developed ectopic brain tissue is seen), we used EGFP-tagged Kv1.5 mRNA. Surprisingly, in contrast to the stage 30 results, at stage 45 all the ectopic neural tissues $(100 \% ; n=20)$ were GFP positive (Fig. $8 B$ ). These results suggest that although ectopic neural tissue induction may begin in both injected cells and in their surrounding neighboring cells and tissues (Fig. 8A), the ectopically induced neural fate persists to stage 45 only in the cells that were injected with hyperpolarizing channels. Their adjacent "recruits" revert to a nonbrain state by stage 45 (Fig. $8 B$ ). This reveals the capability of $V_{\text {mem }}$ signals to affect patterning noncell autonomously, but also highlights the ability of tissues to normalize aberrant cell fates with time if this $V_{\text {mem }}$ level is not directly enforced.

$V_{\text {mem }}$ signaling regulates brain cell proliferation at long range What limits the size of the anterior field that becomes brain? A major factor regulating tissue boundaries in developmental organ formation is the extent of cell proliferation (Stanger, 2008; Joseph and Hermanson, 2010; Shitamukai and Matsuzaki, 2012). Hence we analyzed proliferation within the developing brain of

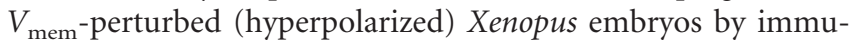
nostaining transverse sections through brain, for phosphorylated histone 3B (H3P; a proliferation marker; Saka and Smith, 2001; Sánchez Alvarado, 2003). Sections anterior to eye and/or through eye were used for analysis of developing brain tissue. In control embryos, mitotic cells were mainly located adjacent to the neural canal (Fig. 9Ai), a region previously reported to be a niche of pluripotent cells from which neural progenitor cells are generated (Götz and Huttner, 2005; Stanger, 2008). Embryos injected with $K v 1.5$ (hyperpolarizing) mRNA into the two dorsal cells at four-cell stage (for targeting neural tissues) showed a small but significant decrease in H3P signal (Fig. 9Aii, $B ; n>11$ for each experimental group, one-way ANOVA, $p<0.001$, with posttests). Surprisingly, embryos injected with $K v 1.5$ (hyperpolarizing) mRNA into two ventral cells at four-cell stage (targeting nonneural tissues) showed a marked increase in the $\mathrm{H} 3 \mathrm{P}$ signal in the developing brain and eye, compared with controls (Fig. 9Ai-iii,B). This increase in the H3P signal was seen mainly in the proliferation niche, with some $\mathrm{H} 3 \mathrm{P}$ signal also observed deeper in the developing brain tissue. We verified our targeting of dorsal and ventral tissue by coinjection of $\beta$-galactosidase mRNA along with $K v 1.5$ and then performing $\mathrm{H} 3 \mathrm{P}$ immunostaining on sections of $\beta$-galactosidasestained embryos (data not shown). Importantly, embryos injected only on the right side (showing $\beta$-galactosidase only on the injected right side of the embryo) revealed increased $\mathrm{H} 3 \mathrm{P}$ signal on both sides (injected right and uninjected left) of the developing brain tissue (data not shown).

To ensure that the increased $\mathrm{H} 3 \mathrm{P}$ signal is not due to cells stuck in the $\mathrm{S}$ phase or $\mathrm{M}$ phase of the cell cycle and to confirm our $\mathrm{H} 3 \mathrm{P}$ results, we used the florescent ubiquitinylation-based cell-cycle indicator (Fucci; Sakaue-Sawano et al., 2008). The two Fucci construct mRNAs, $m K O 2-z C d t 1$ (red fluorescence) and $m A G-z G e m i n i n$ (green fluorescence), were coinjected at 1:2 ratio, respectively, in both cells of two-cell embryos resulting in a homogenous presence of the cell-cycle reporter proteins throughout the embryo. Fucci fluo- 

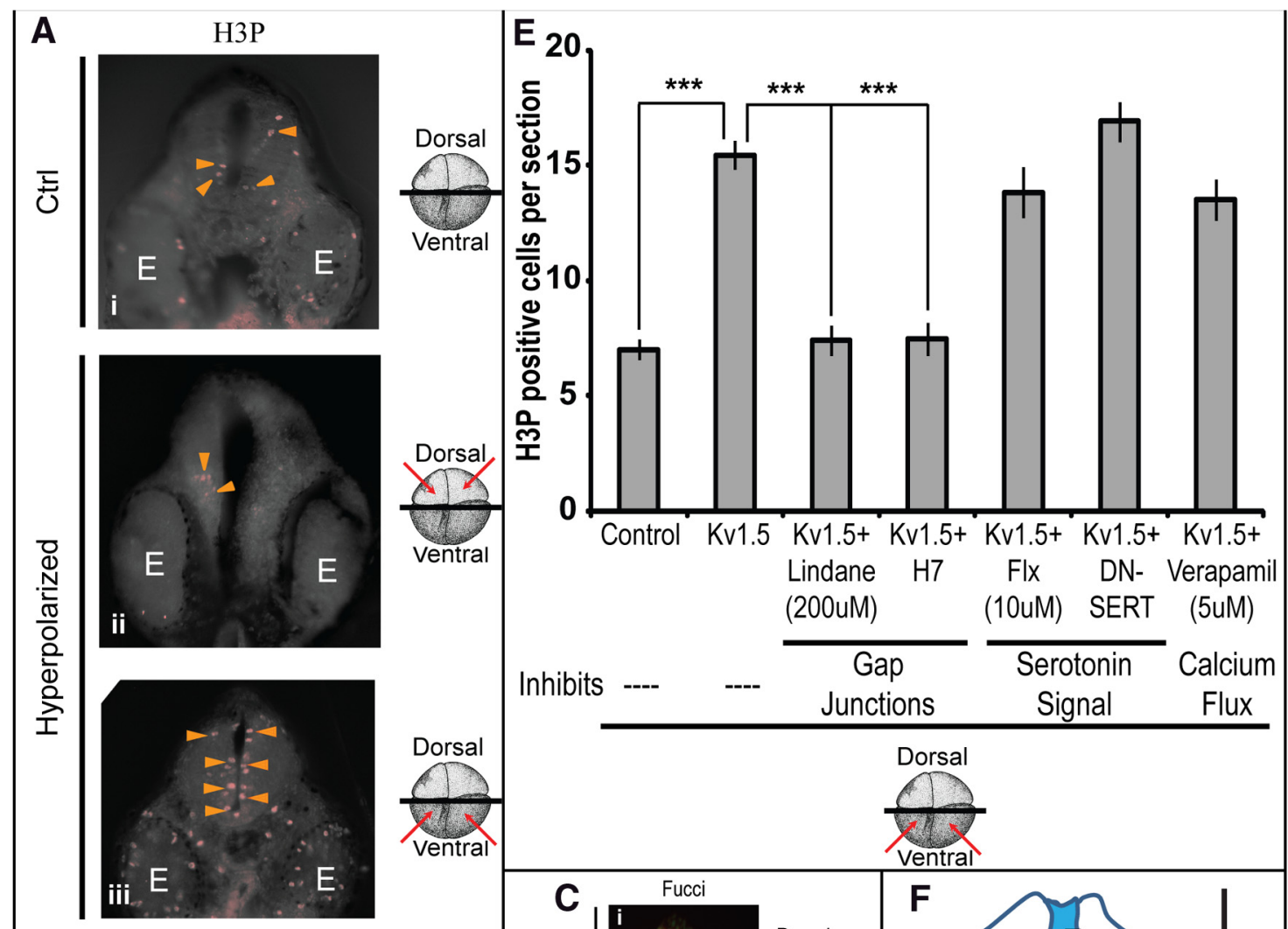

E Eye $\triangle$ H3P stain
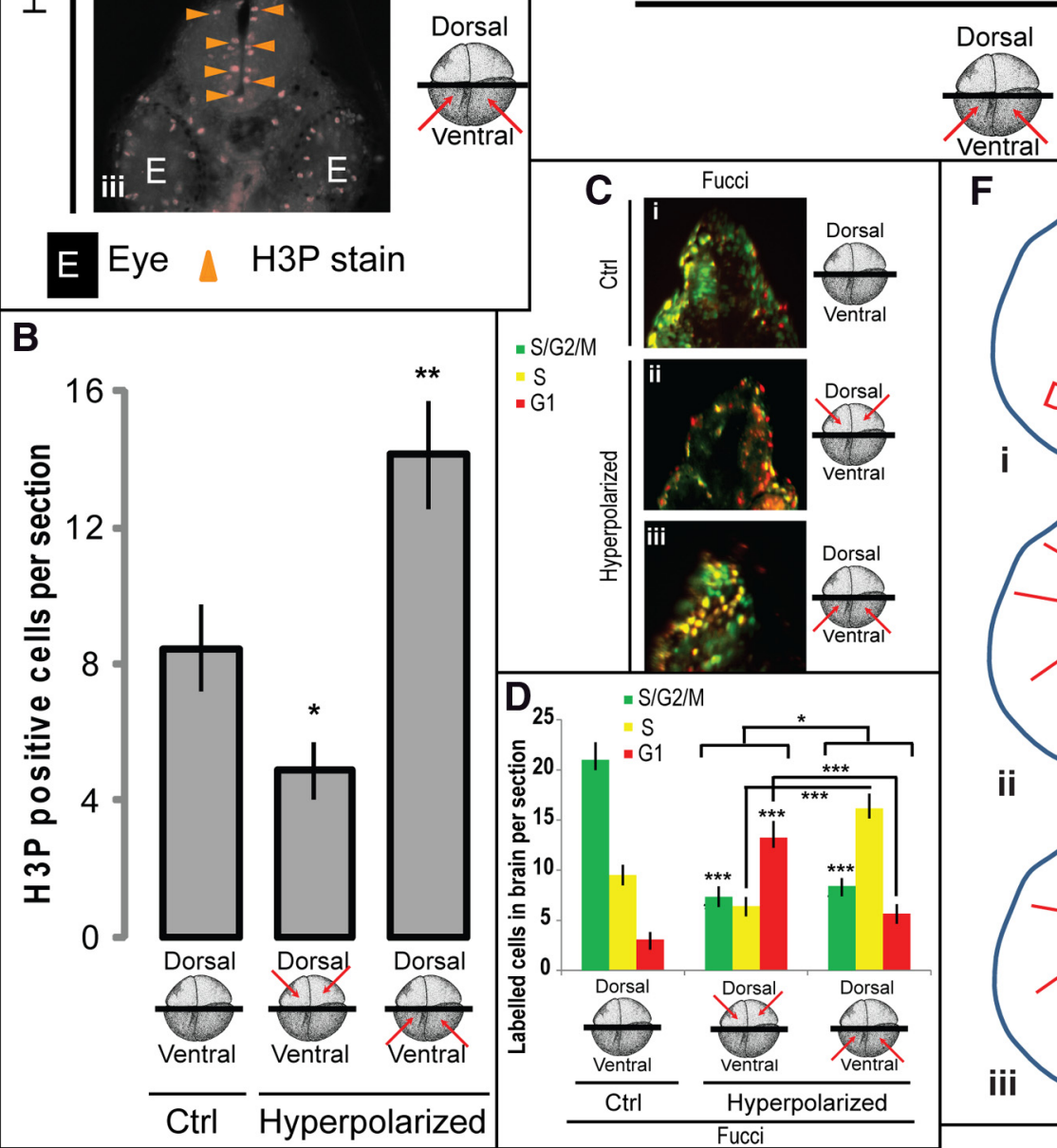

$\mathbf{F}$
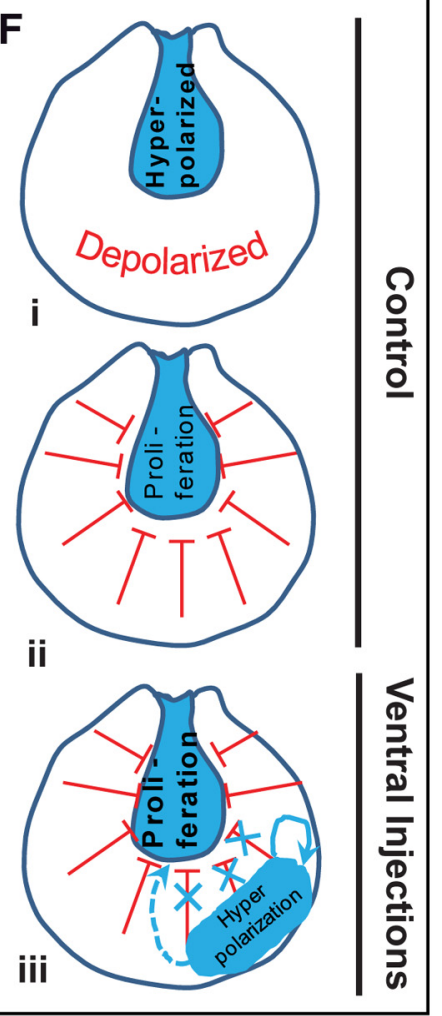

Figure 9. Local and distant $V_{\text {mem }}$ signals regulate the proliferation in the developing brain. $\boldsymbol{A}$, Agarose sections of stage 30 control (uninjected) embryos ( $\boldsymbol{A} \boldsymbol{i}$ ) and embryos microinjected with hyperpolarizing Kv1.5 mRNA (Aii, Aiii) in the indicated blastomeres (red arrows) at four-cell stage [ $n>11$ for each group including controls]. Immunostaining of sections through the developing brain with H3P (Ai-iii) shows a distinct change in the $\mathrm{H} 3 \mathrm{P}$ (orange arrowheads) staining in the developing brains of microinjected embryos with highly increased H3P staining in the ventral-injected embryos compared with uninjected controls. B, Quantification of H3P immunostaining in the agarose sections through developing brains of stage 30 control (uninjected) and Kv1.5 microinjected (red arrows indicate injected blastomeres at four-cell stage) embryos. Dorsal blastomere injections significantly decrease the H3P signal whereas ventral injections significantly increase the H3P signal. Values are mean \pm SEM $(n \geq 10) ;{ }^{*} p<0.05$, ${ }^{* *} p<0.01$, and ${ }^{* * *} p<0.001$ one-way ANOVA with post-test. C, Agarose sections of Fucci-microinjected (both cells at two-cell stage) stage 30 control embryos (Ci) and embryos also microinjected with hyperpolarizing Kv1.5 mRNA (Cii, (iii) in the indicated blastomeres (red arrows) at four-cell stage $[n=12$ for each experimental group]. Fluorescence detection in sections through the developing brain (Ci-iii) shows a distinct change in the cells' fluorescence pattern (indicator of their placement in different stages of cell cycle; green, $S / G_{2} / M$; red, $G_{1}$; yellow, $S$ ) in the developing brains of microinjected embryos, with decreased numbers of green and yellow fluorescent cells $\left(S / G_{2} / M\right.$ phase-dividing cells) and increased red fluorescent cells ( $G_{1}$ nondividing cells) in the dorsal-injected embryos (Figure legend continues.) 
rescence was recorded from the developing brain of $V_{\text {mem }}$-perturbed (hyperpolarized) and control Xenopus embryos that were sectioned through the brain (Fig. 9C). In control embryos, large numbers of cells are in the $\mathrm{S} / \mathrm{G}_{2} / \mathrm{M}$ phase, consistent with developing embryonic brains (green; Fig. $9 C i, D$ ). Very few cells are in the $G_{1}$ phase (red) with a limited number of cells entering the cell cycle $G_{1}$ to $S$ (yellow; Fig. 9Ci,D). Embryos injected with Kv1.5 (hyperpolarizing) mRNA into the two dorsal cells at four-cell stage (for targeting neural tissues) showed a significant decrease in number of cells in $S / G_{2} / M$ phase (green), a slight decrease in number of cells entering from $G_{1}$ to $S$ phase (yellow), and a highly significant increase in number of cells in the nonproliferating $\mathrm{G}_{1}$ phase (red; Fig. $9 \mathrm{Cii}, D ; n=12$ for each experimental group, two-way ANOVA with post-tests). Embryos injected with Kv1.5 (hyperpolarizing) mRNA into two ventral cells at four-cell stage (targeting non-neural tissues) reduced the number of nonproliferating $G_{1}$ cells (red) to almost control levels compared with dorsal injections and dramatically increased the cells entering the $S$ (proliferative) phase (yellow) (Fig. 9Ciii,D). These results support our interpretation of the H3P staining, do not indicate that cells are trapped in M phase, and show a dynamic shift in the brain cells across different stages of cell cycle in response to $V_{\text {mem }}$ changes both locally and at long range.

These results suggest that the channel activity of cells differentially regulates proliferation both locally and at considerable range (across the dorsoventral axis and the embryonic left-right midline); the propagating influence could be the voltage change (via GJ paths) and/or a secondary signal triggered by $V_{\text {mem }}$ change. These results also suggest that both dorsal and ventral $V_{\text {mem }}$ states are likely involved in sculpting the developing neural tissues' morphology.

Which transduction mechanism(s) mediate this remote (ven-

$\leftarrow$

(Figure legend continued.) (Cii), and increased numbers of yellow fluorescent cells ( $G_{1}$ to $S$ phase-cells entering division) in ventrally injected embryos (Ciii), compared with controls (Ci). D, Quantification of Fucci fluorescence (green, red, and yellow) in the agarose sections through developing brains of stage 30 controls (only Fucci-injected) and Kv1.5 (in addition to Fucci)microinjected (red arrows indicate injected blastomeres at four-cell stage) embryos. Kv1.5 microinjection significantly changes the fluorescence pattern of cells compared with the controls. Dorsal blastomere injections significantly decrease green fluorescence and significantly increased red fluorescence whereas ventral blastomere injections significantly increase yellow fluorescence. Values are mean $\pm \operatorname{SEM}(n=12) ;{ }^{*} p<0.05,{ }^{* * *} p<0.01$, and ${ }^{* * *} p<0.001$; two-way ANOVA with post-tests. $E$, Quantification of H3P immunostaining in the agarose sections through developing brains of stage 30 control (uninjected) and Kv1.5 mRNA microinjected into two ventral blastomeres at four-cell stage embryos. Injected embryos were kept with or without the indicated inhibitors. A high incidence of $\mathrm{H} 3 \mathrm{P}$ signal is seen in the brain tissue in $K v 1.5$ microinjected embryos and this effect of Kv1.5 is prevented by Lindane (stages $10-30$ ) and $\mathrm{H} 7$ (respective pharmacological and chimeric dominant-negative blockers of GJC among cells) but not by fluoxetine (Flx; stages 10 -30) or dominant-negative SERT (DN-SERT; a chemical blocker and molecular blocker of the serotonin transporter, respectively) or verapamil (stages $10-30$; a blocker of voltage-gated calcium channels). A one-way ANOVA (values are mean $\pm \mathrm{SEM} ; n \geq 10$ ) analysis with post hoc test showed significant variance among the groups, with Kv1.5 significantly different from control and Kv1.5 + Lindane and Kv1.5 + H7 $\left(^{* * *} p<0.001\right) . F$, Model for $V_{\text {mem }}$ control of neural tissue size by regulating proliferation over long range. The set of studies reported here show that there is a specific degree of hyperpolarized resting membrane potential within the developing neural tissue, with the surrounding tissue depolarized (Fi). This specific degree of hyperpolarized potential regulates the proliferation within that tissue as disrupting this specific hyperpolarization signal decreases the proliferation in the brain. Concurrently, the surrounding depolarized tissues restrict proliferation in the brain tissue over long distance thus governing the tissue size and sculpting the brain tissue (Fii). Hence, when the surrounding tissue is hyperpolarized this restriction is lost and there is increased proliferation in the brain tissue observed (Fiii). These ectopic hyperpolarized tissues not only induce ectopic brain tissues but also might regulate the proliferation within these ectopic brain tissues in conjugation with the surrounding depolarized tissue to bring about sculpting these ectopically induced brain tissues. These results suggest an important role of resting potential distribution in regulating brain tissue size and sculpting. tral) $V_{\text {mem }}$ signal's control over developing brain cells proliferation? To assess this we performed a suppression assay with candidates known to transduce $V_{\text {mem }}$ signal (Levin and Stevenson, 2012; Adams and Levin, 2013; Levin, 2014; Pai and Levin, 2014; Fig. 9E). Kv1.5 (hyperpolarizing) mRNA was injected into two ventral cells of four-cell embryos to disrupt the long-range ventral $V_{\text {mem }}$ signal. Each of the several targets known to connect $V_{\text {mem }}$ changes to downstream steps (Levin and Stevenson, 2012; Adams and Levin, 2013) were blocked one at a time, to determine which would suppress the increase in $\mathrm{H} 3 \mathrm{P}$ staining seen at long range in developing brain tissue (Fig. 9E). Blocking serotonergic signaling via inhibition of SERT transporter [chemically, fluoxetine (stages 10-30) and molecularly via dominant-negative SERT mRNA; Fukumoto et al., 2005b; Blackiston et al., 2011] and blocking VGCCs [chemically, verapamil (stages 10-30)] did not suppress the long-range increase in $\mathrm{H} 3 \mathrm{P}$ staining in the developing brain tissue (Fig. 9E). In contrast, GJ blockade [chemically, Lindane (stages 10-30) and molecularly, using the $\mathrm{H} 7$ chimeric dominant-negative connexin] completely reversed the effect of ventral $V_{\text {mem }}$ modulation on $\mathrm{H} 3 \mathrm{P}$ staining in the developing brain tissue (Fig. $9 E ; n>10$; one-way ANOVA, ${ }^{* *} p<0.001$ post hoc test). These results suggest that the long-range signals regulating proliferation in developing brain tissue are likely transduced through GJ-mediated signaling.

\section{Discussion}

Voltage reporter dyes revealed dynamic developmental changes in resting potential in vivo (Vandenberg et al., 2011; Adams and Levin, 2012). Here, we functionally examine the intense hyperpolarization during neurulation (Fig. 1). While the activity dependence of the sculpting of neural connections is well known (Penn and Shatz, 1999; Kozorovitskiy et al., 2012), here we show for the first time that specific spatial distribution pattern of cells with depolarized and hyperpolarized resting potentials control several facets of large-scale morphogenesis of the brain.

Microinjection of well characterized (Adams and Levin, 2013) ion channel mRNAs regulates $V_{\text {mem }}$ with molecular and spatial specificity; it erases endogenous spatial (differential) distribution patterns of $V_{\text {mem }}$ (Figs. 1A, B, 2A), and also alters the level of polarization of neural and non-neural tissues. Both of these- the spatial distribution patterns of $V_{\text {mem }}$ (borders of isopotential cell groups) and the extent of polarization of specific cells (at key locations within the neural plate) - could encode aspects of patterning information necessary for proper brain morphogenesis. Absolute $V_{\text {mem }}$ has long been known to control cell proliferation and differentiation, while relative $V_{\text {mem }}$ differences between neighboring cells regulate physiological parameters such as the open probability of gap junctions connecting those cells. Subsequent work will tease apart the individual contributions of absolute and relative $V_{\text {mem }}$ levels during normal development.

Altering the endogenous spatial distribution patterns of $V_{\text {mem }}$ (particularly around the developing neural tube) produced defects in brain patterning ranging from smaller forebrain to completely absent nostrils, eyes, forebrain, and significant portions of midbrain, while the rest of the animal developed normally. The use of two distinct means of altering resting potential — chloride channels or potassium channels (Fig. 2; Blackiston et al., 2011; Pai et al., 2012b) - revealed that the phenotype did not rely on any one specific channel protein or ion type. These results point to $V_{\text {mem }}$ (aggregate result of all ion fluxes within a cell) per se, and particularly its spatial distribution pattern, as regulators of brain morphogenesis; channel-specific (nonionic) signaling or chemical effects of chloride 
or potassium ion levels are less likely but cannot be completely ruled out.

How do changes in $V_{\text {mem }}$ alter transcription and proliferation to drive brain morphology defects? A suppression test revealed that the effect of erasing $V_{\text {mem }}$ spatial distribution patterns on brain morphology is mediated by $\mathrm{Ca}^{2+}$ flux through VGCCs and by GJs. GJs may be required via their role in forming the required isopotential cell compartments during morphogenesis or via mediating movement of important signaling molecules (which can include calcium waves). The exact mechanism by which VGCCs participate in transducing hyperpolarization is not yet known, but our data are consistent with the ubiquitous use of calcium as a sensor of voltage change in the mature nervous system. Possibilities include: (1) voltage-dependent effects on cytoskeletal elements that regulate calcium channels (Luga and Wrana, 2013); (2) calcium regulation of gap junctions (Kahlert and Kalluri, 2013), which are important for demarcating coupled cell fields during organogenesis; (3) involvement of hyperpolarizationactivated and cyclic nucleotide-gated channels (Wahl-Schott and Biel, 2009), which also conduct $\mathrm{Ca}^{2+}$ influx (Yu et al., 2004; Michels et al., 2008; Tamura et al., 2009); (4) voltage-driven signaling by regulators of VGCCs such as G $\beta$ of GPCRs, PKA, PKC, and Wnt (Panáková et al., 2010); and (5) entry of calcium via $\mathrm{Ca}^{2+}$ channels by extra driving force (electric potential) provided by hyperpolarization. Novel mechanisms may also be responsible.

Experimental modulation of resting potential alters the normal expression profiles of key forebrain neural precursor transcription factors ( $o t x 2, b f 1$, and $e m x$; Fig. $3 A$ ), consistent with the defects we observed. While these functional data place $V_{\text {mem }}$ upstream of the transcriptional regulation of these targets, we do not know how many other events mediate the control of these transcripts by resting potential. There may be several steps, transcriptional and epigenetic, between the hyperpolarization and the change of expression of these forebrain factors. Moreover, these genes are likely not the only ones that are altered; we are currently pursuing genome-wide analyses to better understand transcriptional responses to $V_{\mathrm{mem}}$ change. Interestingly, the effect of $V_{\mathrm{mem}}$ seems specific for the brain, and does not involve changes in early dorsoventral induction events (since expression of cerberus and chordin at very early stages was completely normal).

Due to downstream control of proliferation and gene expression, endogenous distributions of specific $V_{\text {mem }}$ levels regulate brain morphogenesis. Like any tightly regulated instructive developmental signal, several distinct aspects of the spatiotemporal $V_{\text {mem }}$ gradient are important for forming a normal brain. The first is absolute $V_{\text {mem }}$ range. The $V_{\text {mem }}$ range that initiates eye induction is centered at approximately $-25 \mathrm{mV}$ (Pai et al., 2012b), while that which specifies brain is centered at approximately $-50 \mathrm{mV}$ (Fig. 1), suggesting the testable hypothesis that at least a few different organs (embryonic precursors) may occupy distinct regions of the $V_{\mathrm{mem}}$ scale as a kind of code (akin to the Hox code, perhaps). Importantly, it is likely that this code is defined not only at the level of single cells but is involved in cells measuring the potential of their neighbors, because GJ open/ closed states are regulated by transjunctional voltage difference. Thus, not only absolute but relative $V_{\text {mem }}$ differences are important, because such differences define the borders of physiologically coupled multicellular compartments during organogenesis. For these reasons, correct spatiotemporal distribution of $V_{\text {mem }}$ values is important, to partition the underlying tissue and induce correct gene expression and proliferative states in the right places at the right time.

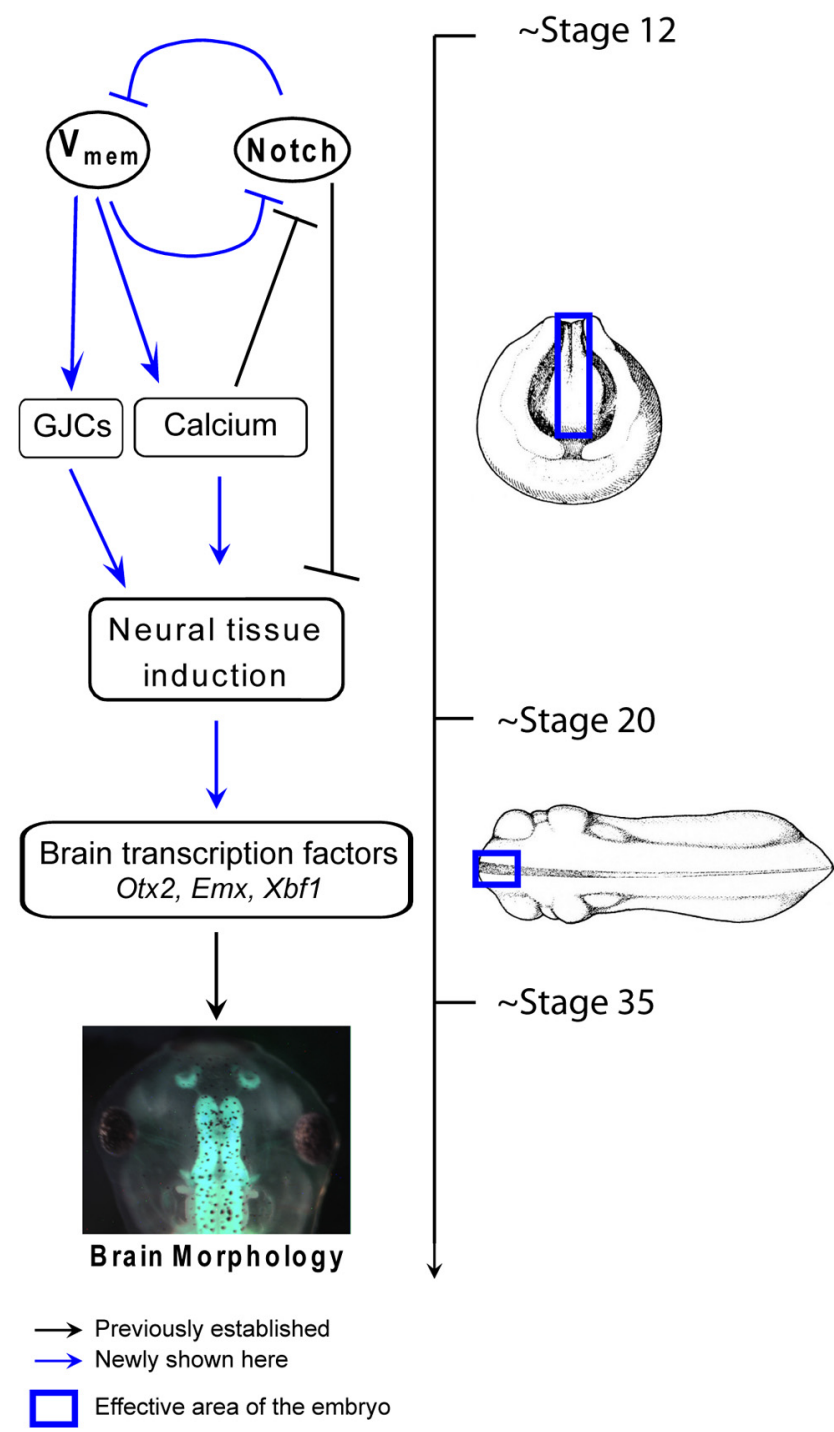

Figure 10. Synthesizing model for $V_{\text {mem }}$ regulation of brain morphology. Model for $V_{\text {mem }}$ Notch integration in directing brain morphology. The set of studies reported here show that specific resting potential change is important for induction of neural tissue. Such a $V_{\text {mem }}{ }^{-}$ mediated signal is strong enough to rescue inhibition of neural tissue induction by the constitutively active notch on brain morphology, suggesting cross talk with notch pathway. Notch, however, is shown to depolarize $V_{\text {mem, }}$, resulting in a feedback loop. Our data also show that the $V_{\text {mem }}$ signal is transduced via calcium and $\mathrm{GJs}$, and also regulates the brain development transcription factors. Together, previous data and our new observations suggest the model schematized here for the interaction of two key factors - biochemical signaling via Notch and bioelectrical signaling via resting potential —in regulating the events that pattern the vertebrate brain.

This kind of "Goldilocks Effect" is increasingly observed also with biochemical signals. For example, Notch, Calcium, Vitamin $\mathrm{D}$, Sonic hedgehog, and Retinoic Acid all operate via a graded response with specific windows. Their levels have to be at just the right values to generate the correct developmental response (Dolphin, 2003; Shi et al., 2009; Hori et al., 2013; Baughman and Lower, 2014). For example; $\mathrm{Ca}^{2+}$ influx into the cells has to be fine-tuned to generate a correct response like neurotransmitter release or muscle contraction and prevent calcium-induced cell damage due to excess $\mathrm{Ca}^{2+}$ influx (Dolphin, 2003). Similarly, how notch signal is integrated with other signaling pathways in the context of particular cell physiology dictates what role notch plays in cell-fate specification (Hori et al., 2013). Windows of 
optimal signaling are especially important here because positive feedback loops, such as the one between Pax6 and Notch (Fig. 5; Pai et al., 2012b), can magnify small differences of signal levels into distinct downstream outcomes. Hence the right range of $V_{\text {mem }}$ may trigger just the right extent of $\mathrm{Ca}^{2+}$ and/or Notch signal resulting in the correct (neural) specification. Such cross talk and feedback loops (different signals generated at different $V_{\text {mem }}$ ranges) may be one of the mechanisms by which different $V_{\text {mem }}$ ranges induce different specification signals.

Two distinct large-scale bioelectric signals impinge on brain patterning: the characteristic region of hyperpolarization within the developing neural tube itself (Figs. 1-3) and the relatively depolarized ventral and lateral tissue encircling the developing neural tube (Figs. 1, 2, 9). The way these two signals act is best exemplified by our results on proliferation in the developing brain tissue. The endogenous hyperpolarization $\left(V_{\text {mem }}\right.$ signal) within the developing neural tube facilitates proliferation locally within the developing brain (Fig. 9), while the depolarizing signal in the surrounding ventral and lateral tissues keeps the neural expansion in check by long-range suppressive action on proliferation (Fig. $9 F$ ). This long-range suppressive action of $V_{\text {mem }}$ signals on proliferation within the developing brain is largely mediated by asyet unidentified signals (bioelectric, biochemical, and/or genetic) through GJCs (Fig. 9E). Such noncell-autonomous signaling has been postulated to be a key feature of organogenesis during embryonic growth (Stanger, 2008), and has been observed during bioelectrical regulation of metastatic transformation (Brown et al., 1994; Blackiston et al., 2011). To our knowledge, this is the first study showing that brain tissue sculpting is regulated by long-range signals from the surrounding non-neural tissues (Fig. $9 F$ ), and that bioelectrical cell state mediates this process. Such a balance between local and long-distance signals may play an important role in other facets (in addition to proliferation) of brain and neural tissue development. This remains an active area of investigation in the laboratory.

Forced activation of Notch, a top-level suppressor of neural tissue formation (Campos-Ortega, 1995), results in drastic mispatterning of the neural tissue (Fig. 5) and surprisingly a loss of the endogenous $V_{\text {mem }}$ (polarization) signal (either via direct effect on $V_{\text {mem }}$ or indirectly by switching cell fate to those with nonconformant $V_{\text {mem }}$ ) during neural tissue patterning. Importantly, enforcing the hyperpolarization state can rescue brain patterning despite overactivation of Notch, suggesting that modulation of bioelectric state may be an important control point for intervention in some birth defects. $\mathrm{Ca}^{2+}$ is known to suppress anti-neural Notch signals directly and via activation of CaMKII signal (Record et al., 2014). This may be one mechanism by which the $V_{\text {mem }}-\mathrm{Ca}^{2+}$ module overrides the activeNotch signal-mediated neural mispatterning (Figs. 5, 10). Similar interactions between $V_{\text {mem }}$ and BMP signaling (Dahal et al., 2012; Swapna and Borodinsky, 2012) broaden the potential applicability of this strategy. Together, these observations about the bidirectional relationship of Notch and $V_{\text {mem }}$ reveal important interplay between resting potential and a major biochemical pathway. Additional possible interactions between biophysical signals and other biochemical and genetic signals involved in brain morphogenesis remain to be discovered.

Ectopic brain tissue can be induced just by generating abnormally hyperpolarized $V_{\text {mem }}$ in a body region. The appearance of ectopic brain involved induction of canonical forebrain markers such as emx and $b f 1$ and neural markers such as Sox 2 and NCAM (Fig. 7; data not shown), suggesting these as possible novel downstream targets of bioelectric induction of ectopic structures. Remarkably, $V_{\text {mem }}$ hyperpolarization induced neural tissues well outside the anterior neural field (e.g., in the tail region; Figs. 6-8; data not shown). Hence, resting potential may serve as a convenient control knob that may expand current ideas about tissue competence limitations. $V_{\text {mem }}$-modulating reagents may be useful to induce or augment production of nerve tissue in regenerative medicine or stem cell bioengineering (Sundelacruz et al., 2013b). While expression of cell reprogramming factors alone results in teratomas in vivo (Abad et al., 2013), we show that coexpression of reprogramming factors $P O U$ and $H B 4$ boosts the efficiency of ectopic brain tissue produced by ectopic $V_{\text {mem }}$ hyperpolarization (Fig. 7; data not shown). These first in vivo data on interaction of reprogramming pathways with bioelectrical signaling are consistent with the known modulation of reprogramming factor phenotypes by ion channel expression (Zhang et al., 2012), and the broader role of $V_{\text {mem }}$ regulation in stem cell biology ( $\mathrm{Ng}$ et al., 2010; Yamashita, 2012; Sundelacruz et al., 2013a). Our data reveal that during early stages, ectopic $V_{\text {mem }}$ hyperpolarization functions across several cell diameters and likely involves gap junctional communication as one of the major molecular mediators of $V_{\text {mem }}$ change, summarized as a model in Figure $8 C$. The integration of GJ dynamics with cellautonomous ion channel circuits to understand global bioelectric properties is a major area of future research (Palacios-Prado and Bukauskas, 2009). While the chemical nature of the GJ-permeable signal is not yet known, ideal candidates include serotonin (Fukumoto et al., 2005a; Levin, 2007) and $\mathrm{Ca}^{2+}$ (Wolszon et al., 1994; Blomstrand et al., 1999).

$V_{\text {mem }}$ hyperpolarization induces new cell proliferation and production of ectopic brain tissue, which cannot be explained by mere toxicity or disruption of housekeeping processes. Instead, it suggests the kind of instructive signaling seen for bioelectric parameters in other contexts (Konig et al., 2004; Sundelacruz et al., 2009; Ng et al., 2010; van Vliet et al., 2010; Pai et al., 2012a, b). Why are only a subset and not all of the ion channel-injected cells (ectopically hyperpolarized) converted into ectopic brain? The $V_{\text {mem }}$ spatial distribution (between ectopically hyperpolarized cells and the surrounding electrically isolated uninjected cells/regions) are likely to be important for brain tissue morphogenesis because it would control GJ open probabilities, and also determine the strength of the driving force for small signaling molecules through the GJs. This same mechanism that normally limits the size of the hyperpolarization-induced endogenous brain may also be limiting the size of the ectopic neural tissue induced outside the head regions. This means that it is not sufficient to induce large regions of hyperpolarization but rather, more subtle gradients have to be established: only those cells lucky enough (given the limitations of channel mRNA injections) to have both the right degree of hyperpolarization and the right $V_{\text {mem }}$ spatial gradient with its neighboring region morphologically develops into brain tissue. We are currently developing optogenetic technologies that will afford us much greater spatial and temporal control of the bioelectrical states we introduce, enabling specific testing of the hypotheses driven by this study's data.

\section{Conclusion}

The resting potentials of local and remote tissues are an important endogenous component of brain sculpting at the level of gene expression and cell proliferation via regulation of factors such as otx2, emx, and $b f 1$. Manipulation of cellular $V_{\text {mem }}$ using chemical and/or genetic reagents rescues brain defects induced by Notch misregulation, can trigger de novo neurogenesis throughout the body, and also synergizes with reprogramming factors (POU and HB4). A variety of ion channels can achieve the needed $V_{\text {mem }}$ state; thus, a plethora of human-approved ion channel drugs could be used to trigger desired changes in $V_{\text {mem }}$ 
properties and thus control cell behavior of local and remote tissues. A central component of the model (Fig. 10) is feedback interaction between $V_{\text {mem }}$ signals and Notch (directly or indirectly) in establishing neural fate (similar feedback interactions with other key signals like FGF, BMP, and Wnt are also likely).These data identify a new role for $V_{\text {mem }}$ signaling in development, reveal long-range signaling impinging on brain morphogenesis, and suggest $V_{\text {mem }}$ modulation as a tractable strategy for manipulating neurogenesis and neural patterning in the context of birth defects, regenerative medicine, and in vitro bioengineering.

\section{References}

Abad M, Mosteiro L, Pantoja C, Cañamero M, Rayon T, Ors I, Graña O, Megías D, Dominguez O, Martínez D, Manzanares M, Ortega S, Serrano M (2013) Reprogramming in vivo produces teratomas and iPS cells with totipotency features. Nature 502:340-345. CrossRef Medline

Acampora D, Mazan S, Lallemand Y, Avantaggiato V, Maury M, Simeone A, Brûlet P (1995) Forebrain and midbrain regions are deleted in Otx2-/mutants due to a defective anterior neuroectoderm specification during gastrulation. Development 121:3279-3290. Medline

Adams DS, Levin M (2012) Measuring resting membrane potential using the fluorescent voltage reporters DiBAC4(3) and CC2-DMPE. Cold Spring Harb Protoc 2012:459-464. CrossRef Medline

Adams DS, Levin M (2013) Endogenous voltage gradients as mediators of cell-cell communication: strategies for investigating bioelectrical signals during pattern formation. Cell Tissue Res 352:95-122. CrossRef Medline

Adams DS, Robinson KR, Fukumoto T, Yuan S, Albertson RC, Yelick P, Kuo L, McSweeney M, Levin M (2006) Early, H+-V-ATPase-dependent proton flux is necessary for consistent left-right patterning of nonmammalian vertebrates. Development 133:1657-1671. CrossRef Medline

Artavanis-Tsakonas S, Matsuno K, Fortini ME (1995) Notch signaling. Science 268:225-232. CrossRef Medline

Aruga J, Mikoshiba K (2011) Role of BMP, FGF, calcium signaling, and Zic proteins in vertebrate neuroectodermal differentiation. Neurochem Res 36:1286-1292. CrossRef Medline

Aw S, Adams DS, Qiu D, Levin M (2008) H, K-ATPase protein localization and Kir4.1 function reveal concordance of three axes during early determination of left-right asymmetry. Mech Dev 125:353-372. CrossRef Medline

Aw S, Koster JC, Pearson W, Nichols CG, Shi NQ, Carneiro K, Levin M (2010) The ATP-sensitive K(+)-channel (K(ATP)) controls early leftright patterning in Xenopus and chick embryos. Dev Biol 346:39-53. CrossRef Medline

Balak K, Jacobson M, Sunshine J, Rutishauser U (1987) Neural cell adhesion molecule expression in Xenopus embryos. Dev Biol 119:540-550. CrossRef Medline

Barker EL, Moore KR, Rakhshan F, Blakely RD (1999) Transmembrane domain I contributes to the permeation pathway for serotonin and ions in the serotonin transporter. J Neurosci 19:4705-4717. Medline

Baughman RP, Lower EE (2014) Goldilocks, vitamin D and sarcoidosis. Arthritis Res Ther 16:111. CrossRef Medline

Beane WS, Morokuma J, Lemire JM, Levin M (2013) Bioelectric signaling regulates head and organ size during planarian regeneration. Development 140:313-322. CrossRef Medline

Beck CW, Slack JM (1999) A developmental pathway controlling outgrowth of the Xenopus tail bud. Development 126:1611-1620. Medline

Beck CW, Slack JM (2002) Notch is required for outgrowth of the Xenopus tail bud. Int J Dev Biol 46:255-258. Medline

Beck CW, Whitman M, Slack JM (2001) The role of BMP signaling in outgrowth and patterning of the Xenopus tail bud. Dev Biol 238:303-314. CrossRef Medline

Bertoli A, Moran O, Conti F (1994) Activation and deactivation properties of rat brain $\mathrm{K}+$ channels of the Shaker-related subfamily. Eur Biophys J 23:379-384. CrossRef Medline

Blackiston D, Vandenberg LN, Levin M (2010) High-throughput Xenopus laevis immunohistochemistry using agarose sections. Cold Spring Harb Protoc 2010:pdb prot5532. CrossRef Medline

Blackiston D, Adams DS, Lemire JM, Lobikin M, Levin M (2011) Transmembrane potential of $\mathrm{GlyCl}$-expressing instructor cells induces a neoplastic-like conversion of melanocytes via a serotonergic pathway. Dis Model Mech 4:67-85. CrossRef Medline
Blackiston DJ, Anderson GM, Rahman N, Bieck C, Levin M (2015) A novel method for inducing nerve growth via modulation of host resting potential: gap junction-mediated and serotonergic signaling mechanisms. Neurotherapeutics 12:170-184. CrossRef Medline

Blackshaw SE, Warner AE (1976) Alterations in resting membrane properties during neural plate stages of development of the nervous system. J Physiol 255:231-247. CrossRef Medline

Blomstrand F, Aberg ND, Eriksson PS, Hansson E, Rönnbäck L (1999) Extent of intercellular calcium wave propagation is related to gap junction permeability and level of connexin- 43 expression in astrocytes in primary cultures from four brain regions. Neuroscience 92:255-265. CrossRef Medline

Bourguignon C, Li J, Papalopulu N (1998) XBF-1, a winged helix transcription factor with dual activity, has a role in positioning neurogenesis in Xenopus competent ectoderm. Development 125:4889-4900. Medline

Bouwmeester T, Kim S, Sasai Y, Lu B, De Robertis EM (1996) Cerberus is a head-inducing secreted factor expressed in the anterior endoderm of Spemann's organizer. Nature 382:595-601. CrossRef Medline

Brackenbury WJ (2012) Voltage-gated sodium channels and metastatic disease. Channels 6:352-361. CrossRef Medline

Brown RH, Yang LH, Walker SD, Lynch MG, Martinez LA, Wilson LA (1994) Treatment of bleb infection after glaucoma surgery. Arch Ophthalmol 112:57-61. CrossRef Medline

Burr HS (1932) An electro-dynamic theory of development suggested by studies of proliferation rates in the brain of Amblystoma. J Comp Neurol 56:347-371. CrossRef

Campos-Ortega JA (1995) Genetic mechanisms of early neurogenesis in Drosophila melanogaster. Mol Neurobiol 10:75-89. CrossRef Medline

Dahal GR, Rawson J, Gassaway B, Kwok B, Tong Y, Ptácek LJ, Bates E (2012) An inwardly rectifying $\mathrm{K}+$ channel is required for patterning. Development 139:3653-3664. CrossRef Medline

Davies DL, Trudell JR, Mihic SJ, Crawford DK, Alkana RL (2003) Ethanol potentiation of glycine receptors expressed in Xenopus oocytes antagonized by increased atmospheric pressure. Alcohol Clin Exp Res 27:743755. CrossRef Medline

de Felipe P, Luke GA, Hughes LE, Gani D, Halpin C, Ryan MD (2006) E unum pluribus: multiple proteins from a self-processing polyprotein. Trends Biotechnol 24:68-75. CrossRef Medline

Deisseroth K, Singla S, Toda H, Monje M, Palmer TD, Malenka RC (2004) Excitation-neurogenesis coupling in adult neural stem/progenitor cells. Neuron 42:535-552. CrossRef Medline

Dolmetsch RE, Xu K, Lewis RS (1998) Calcium oscillations increase the efficiency and specificity of gene expression. Nature 392:933-936. CrossRef Medline

Dolphin AC (2003) G protein modulation of voltage-gated calcium channels. Pharmacol Rev 55:607-627. CrossRef Medline

Eagleson GW, Theisen S (2008) Stage-specific effects of retinoic acid on gene expression during forebrain development. Brain Res Bull 75:281288. CrossRef Medline

Eagleson GW, Johnson-Meeter LJ, Frideres J (2001) Effects of retinoic acid upon eye field morphogenesis and differentiation. Dev Dyn 221:350-364. CrossRef Medline

Fakler B, Bond CT, Adelman JP, Ruppersberg JP (1996) Heterooligomeric assembly of inward-rectifier $\mathrm{K}+$ channels from subunits of different subfamilies: Kir2.1 (IRK1) and Kir4.1 (BIR10). Pflugers Arch 433:77-83. CrossRef Medline

Fuhrmann S (2010) Eye morphogenesis and patterning of the optic vesicle. Curr Top Dev Biol 93:61-84. CrossRef Medline

Fukumoto T, Kema IP, Levin M (2005a) Serotonin signaling is a very early step in patterning of the left-right axis in chick and frog embryos. Curr Biol 15:794-803. CrossRef Medline

Fukumoto T, Blakely R, Levin M (2005b) Serotonin transporter function is an early step in left-right patterning in chick and frog embryos. Dev Neurosci 27:349-363. CrossRef Medline

Gaete M, Muñoz R, Sanchez N, Tampe R, Moreno M, Contreras EG, Lee-Liu D, Larraín J (2012) Spinal cord regeneration in Xenopus tadpoles proceeds through activation of Sox2-positive cells. Neural Dev 7:13. CrossRef Medline

Gillespie JI (1983) The distribution of small ions during the early development of Xenopus laevis and Ambystoma mexicanum embryos. J Physiol 344:359-377. CrossRef Medline 
Götz M, Huttner WB (2005) The cell biology of neurogenesis. Nat Rev Mol Cell Biol 6:777-788. CrossRef Medline

Harada T, Harada C, Parada LF (2007) Molecular regulation of visual system development: more than meets the eye. Genes Dev 21:367-378. CrossRef Medline

Harland RM (1991) In situ hybridization: an improved whole mount method for Xenopus embryos. In: Xenopus laevis: practical uses in cell and molecular biology (Kay BK, Peng HB, eds), pp 685-695. San Diego, CA: Academic.

Harvey KF, Hariharan IK (2012) The hippo pathway. Cold Spring Harb Perspect Biol 4:a011288. CrossRef Medline

Hori K, Sen A, Artavanis-Tsakonas S (2013) Notch signaling at a glance. J Cell Sci 126:2135-2140. CrossRef Medline

Hough E, Beech DJ, Sivaprasadarao A (2000) Identification of molecular regions responsible for the membrane trafficking of Kir6.2. Pflugers Arch 440:481-487. CrossRef Medline

Joseph B, Hermanson O (2010) Molecular control of brain size: regulators of neural stem cell life, death and beyond. Exp Cell Res 316:1415-1421. CrossRef Medline

Jullien J, Astrand C, Halley-Stott RP, Garrett N, Gurdon JB (2010) Characterization of somatic cell nuclear reprogramming by oocytes in which a linker histone is required for pluripotency gene reactivation. Proc Natl Acad Sci U S A 107:5483-5488. CrossRef Medline

Kahlert C, Kalluri R (2013) Exosomes in tumor microenvironment influence cancer progression and metastasis. J Mol Med 91:431-437. CrossRef Medline

Konig S, Hinard V, Arnaudeau S, Holzer N, Potter G, Bader CR, Bernheim L (2004) Membrane hyperpolarization triggers myogenin and myocyte enhancer factor-2 expression during human myoblast differentiation. J Biol Chem 279:28187-28196. CrossRef Medline

Kozorovitskiy Y, Saunders A, Johnson CA, Lowell BB, Sabatini BL (2012) Recurrent network activity drives striatal synaptogenesis. Nature 485: 646-650. CrossRef Medline

Kroll KL, Amaya E (1996) Transgenic Xenopus embryos from sperm nuclear transplantations reveal FGF signaling requirements during gastrulation. Development 122:3173-3183. Medline

Leclerc C, Néant I, Webb SE, Miller AL, Moreau M (2006) Calcium transients and calcium signalling during early neurogenesis in the amphibian embryo Xenopus laevis. Biochim Biophys Acta 1763:1184-1191. CrossRef Medline

Levin M (2007) Gap junctional communication in morphogenesis. Prog Biophys Mol Biol 94:186-206. CrossRef Medline

Levin M (2013) Reprogramming cells and tissue patterning via bioelectrical pathways: molecular mechanisms and biomedical opportunities. Wiley Interdiscip Rev Syst Biol Med 5:657-676. CrossRef Medline

Levin M (2014) Endogenous bioelectrical networks store non-genetic patterning information during development and regeneration. J Physiol 592: 2295-2305. CrossRef Medline

Levin M, Mercola M (1998) Gap junctions are involved in the early generation of left-right asymmetry. Dev Biol 203:90-105. CrossRef Medline

Levin M, Stevenson CG (2012) Regulation of cell behavior and tissue patterning by bioelectrical signals: challenges and opportunities for biomedical engineering. Annu Rev Biomed Eng 14:295-323. CrossRef Medline

Levin M, Thorlin T, Robinson KR, Nogi T, Mercola M (2002) Asymmetries in $\mathrm{H}+/ \mathrm{K}+$-ATPase and cell membrane potentials comprise a very early step in left-right patterning. Cell 111:77-89. CrossRef Medline

Li JY, Joyner AL (2001) Otx2 and Gbx2 are required for refinement and not induction of mid-hindbrain gene expression. Development 128:49794991. Medline

Lin G, Chen Y, Slack JM (2012) Transgenic analysis of signaling pathways required for Xenopus tadpole spinal cord and muscle regeneration. Anat Rec 295:1532-1540. CrossRef Medline

Linder A, Fjell C, Levin A, Walley KR, Russell JA, Boyd JH (2014) Small acute increases in serum creatinine are associated with decreased longterm survival in the critically ill. Am J Respir Crit Care Med 189:10751081. CrossRef Medline

Luga V, Wrana JL (2013) Tumor-stroma interaction: revealing fibroblastsecreted exosomes as potent regulators of Wnt-planar cell polarity signaling in cancer metastasis. Cancer Res 73:6843-6847. CrossRef Medline

Marsh-Armstrong N, Huang H, Berry DL, Brown DD (1999) Germ-line transmission of transgenes in Xenopus laevis. Proc Natl Acad Sci U S A 96:14389-14393. CrossRef Medline
McCaig CD, Rajnicek AM, Song B, Zhao M (2005) Controlling cell behavior electrically: current views and future potential. Physiol Rev 85:943-978. CrossRef Medline

Michels G, Brandt MC, Zagidullin N, Khan IF, Larbig R, van Aaken S, Wippermann J, Hoppe UC (2008) Direct evidence for calcium conductance of hyperpolarization-activated cyclic nucleotide-gated channels and human native If at physiological calcium concentrations. Cardiovasc Res 78:466-475. CrossRef Medline

Monteiro J, Aires R, Becker JD, Jacinto A, Certal AC, Rodríguez-León J (2014) V-ATPase proton pumping activity is required for adult zebrafish appendage regeneration. PLoS One 9:e92594. CrossRef Medline

Moody SA (1987) Fates of the blastomeres of the 32-cell-stage Xenopus embryo. Dev Biol 122:300-319. CrossRef Medline

Moreau M, Leclerc C (2004) The choice between epidermal and neural fate: a matter of calcium. Int J Dev Biol 48:75-84. CrossRef Medline

Mukhopadhyay P, Brock G, Appana S, Webb C, Greene RM, Pisano MM (2011) MicroRNA gene expression signatures in the developing neural tube. Birth Defects Res A Clin Mol Teratol 91:744-762. CrossRef Medline

Muzio L, Mallamaci A (2003) Emx1, emx2 and pax6 in specification, regionalization and a realization of the cerebral cortex. Cereb Cortex 13: 641-647. CrossRef Medline

Ng SY, Chin CH, Lau YT, Luo J, Wong CK, Bian ZX, Tsang SY (2010) Role of voltage-gated potassium channels in the fate determination of embryonic stem cells. J Cell Physiol 224:165-177. CrossRef Medline

Nieuwkoop PD, Faber J (1967) Normal table of Xenopus laevis (Daudin), Ed 2. Amsterdam: North-Holland Publishing Company.

Nuckels RJ, Ng A, Darland T, Gross JM (2009) The vacuolar-ATPase complex regulates retinoblast proliferation and survival, photoreceptor morphogenesis, and pigmentation in the zebrafish eye. Invest Ophthalmol Vis Sci 50:893-905. CrossRef Medline

Onkal R, Mattis JH, Fraser SP, Diss JK, Shao D, Okuse K, Djamgoz MB (2008) Alternative splicing of Nav1.5: an electrophysiological comparison of 'neonatal' and 'adult' isoforms and critical involvement of a lysine residue. J Cell Physiol 216:716-726. CrossRef Medline

Pai VP, Levin M (2014) Bioelectric control of stem cell function. In: Stem cells: from basic research to therapy (Calegari F, Waskov C, eds), pp 106-148. Boca Raton, FL: CRC.

Pai VP, Vandenberg LN, Blackiston D, Levin M (2012a) Neurally derived tissues in Xenopus laevis embryos exhibit a consistent bioelectrical leftright asymmetry. Stem Cells Int 2012:353491. CrossRef Medline

Pai VP, Aw S, Shomrat T, Lemire JM, Levin M (2012b) Transmembrane voltage potential controls embryonic eye patterning in Xenopus laevis. Development 139:313-323. CrossRef Medline

Palacios-Prado N, Bukauskas FF (2009) Heterotypic gap junction channels as voltage-sensitive valves for intercellular signaling. Proc Natl Acad Sci U S A 106:14855-14860. CrossRef Medline

Panáková D, Werdich AA, Macrae CA (2010) Wnt11 patterns a myocardial electrical gradient through regulation of the L-type $\mathrm{Ca}(2+)$ channel. $\mathrm{Na}-$ ture 466:874-878. CrossRef Medline

Pannese M, Polo C, Andreazzoli M, Vignali R, Kablar B, Barsacchi G, Boncinelli E (1995) The Xenopus homologue of Otx2 is a maternal homeobox gene that demarcates and specifies anterior body regions. Development 121:707-720. Medline

Paul DL, Yu K, Bruzzone R, Gimlich RL, Goodenough DA (1995) Expression of a dominant negative inhibitor of intercellular communication in the early Xenopus embryo causes delamination and extrusion of cells. Development 121:371-381. Medline

Penn AA, Shatz CJ (1999) Brain waves and brain wiring: the role of endogenous and sensory-driven neural activity in development. Pediatr Res 45:447-458. CrossRef Medline

Perathoner S, Daane JM, Henrion U, Seebohm G, Higdon CW, Johnson SL, Nüsslein-Volhard C, Harris MP (2014) Bioelectric signaling regulates size in zebrafish fins. PLoS Genet 10:e1004080. CrossRef Medline

Pratt KG, Khakhalin AS (2013) Modeling human neurodevelopmental disorders in the Xenopus tadpole: from mechanisms to therapeutic targets. Dis Model Mech 6:1057-1065. CrossRef Medline

Properzi F, Logozzi M, Fais S (2013) Exosomes: the future of biomarkers in medicine. Biomark Med 7:769-778. CrossRef Medline

Pullar CE (2011) The physiology of bioelectricity in development, tissue regeneration, and cancer. Boca Raton, FL: CRC

Quick MW (2003) Regulating the conducting states of a mammalian serotonin transporter. Neuron 40:537-549. CrossRef Medline 
Record M, Carayon K, Poirot M, Silvente-Poirot S (2014) Exosomes as new vesicular lipid transporters involved in cell-cell communication and various pathophysiologies. Biochim Biophys Acta 1841:108-120. CrossRef Medline

Saka Y, Smith JC (2001) Spatial and temporal patterns of cell division during early Xenopus embryogenesis. Dev Biol 229:307-318. CrossRef Medline

Sakaue-Sawano A, Kurokawa H, Morimura T, Hanyu A, Hama H, Osawa H, Kashiwagi S, Fukami K, Miyata T, Miyoshi H, Imamura T, Ogawa M, Masai H, Miyawaki A (2008) Visualizing spatiotemporal dynamics of multicellular cell-cycle progression. Cell 132:487-498. CrossRef Medline

Sánchez Alvarado A (2003) The freshwater planarian Schmidtea mediterranea: embryogenesis, stem cells and regeneration. Curr Opin Genet Dev 13:438-444. CrossRef Medline

Sasai Y, Lu B, Steinbeisser H, Geissert D, Gont LK, De Robertis EM (1994) Xenopus chordin: a novel dorsalizing factor activated by organizerspecific homeobox genes. Cell 79:779-790. CrossRef Medline

Shan Q, Haddrill JL, Lynch JW (2001) Ivermectin, an unconventional agonist of the glycine receptor chloride channel. J Biol Chem 276:1255612564. CrossRef Medline

Shi R, Borgens RB (1995) Three-dimensional gradients of voltage during development of the nervous system as invisible coordinates for the establishment of embryonic pattern. Dev Dyn 202:101-114. CrossRef Medline

Shi W, Xu J, Warburton D (2009) Development, repair and fibrosis: what is common and why it matters. Respirology 14:656-665. CrossRef Medline

Shitamukai A, Matsuzaki F (2012) Control of asymmetric cell division of mammalian neural progenitors. Dev Growth Differ 54:277-286. CrossRef Medline

Sive HL, Grainger RM, Harland RM (2000) Early development of Xenopus laevis. New York: Cold Spring Harbor Laboratory.

Snir M, Ofir R, Elias S, Frank D (2006) Xenopus laevis POU91 protein, an Oct3/4 homologue, regulates competence transitions from mesoderm to neural cell fates. EMBO J 25:3664-3674. CrossRef Medline

Spitzer NC (2006) Electrical activity in early neuronal development. Nature 444:707-712. CrossRef Medline

Stanger BZ (2008) Organ size determination and the limits of regulation. Cell Cycle 7:318-324. CrossRef Medline

Strutz-Seebohm N, Gutcher I, Decher N, Steinmeyer K, Lang F, Seebohm G (2007) Comparison of potent Kv1.5 potassium channel inhibitors reveals the molecular basis for blocking kinetics and binding mode. Cell Physiol Biochem 20:791-800. CrossRef Medline

Suh H, Consiglio A, Ray J, Sawai T, D’Amour KA, Gage FH (2007) In vivo fate analysis reveals the multipotent and self-renewal capacities of Sox $2+$ neural stem cells in the adult hippocampus. Cell Stem Cell 1:515-528. CrossRef Medline

Sundelacruz S, Levin M, Kaplan DL (2009) Role of membrane potential in the regulation of cell proliferation and differentiation. Stem Cell Rev 5:231-246. CrossRef Medline

Sundelacruz S, Levin M, Kaplan DL (2013a) Depolarization alters phenotype, maintains plasticity of predifferentiated mesenchymal stem cells. Tissue Eng Part A 19:1889-1908. CrossRef Medline

Sundelacruz S, Li C, Choi YJ, Levin M, Kaplan DL (2013b) Bioelectric mod- ulation of wound healing in a 3D in vitro model of tissue-engineered bone. Biomaterials 34:6695-6705. CrossRef Medline

Swapna I, Borodinsky LN (2012) Interplay between electrical activity and bone morphogenetic protein signaling regulates spinal neuron differentiation. Proc Natl Acad Sci U S A 109:16336-16341. CrossRef Medline

Szymczak-Workman AL, Vignali KM, Vignali DA (2012) Design and construction of 2A peptide-linked multicistronic vectors. Cold Spring Harb Protoc 2012:199-204. CrossRef Medline

Tamura A, Ogura T, Uemura H, Reien Y, Kishimoto T, Nagai T, Komuro I, Miyazaki M, Nakaya H (2009) Effects of antiarrhythmic drugs on the hyperpolarization-activated cyclic nucleotide-gated channel current. J Pharmacol Sci 110:150-159. CrossRef Medline

Thompson DW (1942) On growth and form. Cambridge, UK: Cambridge UP.

Tseng A, Levin M (2013) Cracking the bioelectric code: probing endogenous ionic controls of pattern formation. Commun Integr Biol 6:e22595. CrossRef Medline

van Vliet $\mathrm{P}$, de Boer TP, van der Heyden MA, El Tamer MK, Sluijter JP, Doevendans PA, Goumans MJ (2010) Hyperpolarization induces differentiation in human cardiomyocyte progenitor cells. Stem Cell Rev 6:178-185. CrossRef Medline

Vandenberg LN, Levin M (2010) Far from solved: a perspective on what we know about early mechanisms of left-right asymmetry. Dev Dyn 239: 3131-3146. CrossRef Medline

Vandenberg LN, Morrie RD, Adams DS (2011) V-ATPase-dependent ectodermal voltage and $\mathrm{pH}$ regionalization are required for craniofacial morphogenesis. Dev Dyn 240:1889-1904. CrossRef Medline

Wahl-Schott C, Biel M (2009) HCN channels: structure, cellular regulation and physiological function. Cell Mol Life Sci 66:470-494. CrossRef Medline

Warner AE (1985) The role of gap junctions in amphibian development. J Embryol Exp Morphol 89 [Suppl]:365-380. Medline

Wendler F, Bota-Rabassedas N, Franch-Marro X (2013) Cancer becomes wasteful: emerging roles of exosomes(dagger) in cell-fate determination. J Extracell Vesicles 2. CrossRef

Wolszon LR, Rehder V, Kater SB, Macagno ER (1994) Calcium wave fronts that cross gap junctions may signal neuronal death during development. J Neurosci 14:3437-3448. Medline

Yamashita M (2012) Ion channel activities in neural stem cells of the neuroepithelium. Stem Cells Int 2012:247670. CrossRef Medline

Yu X, Duan KL, Shang CF, Yu HG, Zhou Z (2004) Calcium influx through hyperpolarization-activated cation channels (I(h) channels) contributes to activity-evoked neuronal secretion. Proc Natl Acad Sci U S A 101: 1051-1056. CrossRef Medline

Zhang J, Chan YC, Ho JC, Siu CW, Lian Q, Tse HF (2012) Regulation of cell proliferation of human induced pluripotent stem cell-derived mesenchymal stem cells via ether à go-go 1 (hEAG1) potassium channel. Am J Physiol Cell Physiol 303:C115-C125. CrossRef Medline

Zhao B, Tumaneng K, Guan KL (2011) The Hippo pathway in organ size control, tissue regeneration and stem cell self-renewal. Nat Cell Biol 13: 877-883. CrossRef Medline

Zuber ME (2010) Eye field specification in Xenopus laevis. Curr Top Dev Biol 93:29-60. CrossRef Medline 